NBER WORKING PAPER SERIES

\title{
GETTING THE PRICE RIGHT? THE IMPACT OF COMPETITIVE BIDDING IN THE MEDICARE PROGRAM
}

\author{
Hui Ding \\ Mark Duggan \\ Amanda Starc \\ Working Paper 28457 \\ http://www.nber.org/papers/w28457 \\ NATIONAL BUREAU OF ECONOMIC RESEARCH \\ 1050 Massachusetts Avenue \\ Cambridge, MA 02138 \\ February 2021
}

We thank seminar participants at Stanford and the ASSA meetings, especially Zack Cooper, for helpful comments. The views expressed in this paper are solely those of the authors and do not necessarily represent the views of the institutions or other individuals mentioned above, nor of the National Bureau of Economic Research. All errors are our own. The views expressed herein are those of the authors and do not necessarily reflect the views of the National Bureau of Economic Research.

NBER working papers are circulated for discussion and comment purposes. They have not been peer-reviewed or been subject to the review by the NBER Board of Directors that accompanies official NBER publications.

(C) 2021 by Hui Ding, Mark Duggan, and Amanda Starc. All rights reserved. Short sections of text, not to exceed two paragraphs, may be quoted without explicit permission provided that full credit, including $\odot$ notice, is given to the source. 
Getting the Price Right? The Impact of Competitive Bidding in the Medicare Program

Hui Ding, Mark Duggan, and Amanda Starc

NBER Working Paper No. 28457

February 2021

JEL No. I11

\section{ABSTRACT}

We study Medicare's competitive bidding program (CBP) for durable medical equipment (DME). We exploit Medicare claims data to examine both prices and utilization, focusing on continuous positive airway pressure (CPAP) devices to treat sleep apnea. We find that spending falls by $47.2 \%$ percent after a highly imperfect bidding mechanism is introduced. The effect is almost entirely driven by a $44.8 \%$ price reduction, though quantities also fall by $4.3 \%$. To disentangle supply and demand, we leverage differential cost sharing across Medicare recipients. We measure a demand elasticity of -0.272 and find that quantity reductions are concentrated among less clinically appropriate groups.

Hui Ding

Stanford University

khding@stanford.edu

Mark Duggan

Stanford University

Department of Economics

579 Serra Mall

Stanford, CA 94305-6072

and NBER

mgduggan@stanford.edu
Amanda Starc

Kellogg School of Management

Northwestern University

2211 Campus Drive

Evanston, IL 60208

and NBER

amanda.starc@kellogg.northwestern.edu 


\section{Introduction}

Prices convey information about consumer willingness to pay for a good or service and about its cost of production. Yet in many healthcare markets, the information aggregation properties of prices are distorted. Most insured consumers do not face market prices and reimbursements are often set administratively. Prices may be substantially different from a competitive price and can be influenced by medical specialty societies, potentially leading to regulatory capture (Chan and Dickstein, 2019). Market price-setting mechanisms may also be imperfect. For example, in healthcare, there is an implicit reliance on administered prices (Clemens and Gottlieb, 2017; Clemens et al., 2017) and firms can exert substantial market power (Cooper et al., 2019). Perhaps as a result, high prices are a key feature of relatively high healthcare costs in the United States (Anderson et al., 2003). In this paper, we examine how market institutions can control health care costs; specifically, we measure the impact of a shift from administered prices to a more marketbased mechanism.

The Medicare program provides benefits to 62 million U.S. residents in 2020 at a projected annual cost of more than $\$ 800$ billion (CMS, 2020a,b). For most Medicare recipients, the federal government directly reimburses hospitals, physicians, and other health care providers for the services delivered to patients. Prices for each service are set by a complicated set of regulations that vary by service type. ${ }^{1}$ In part due to concerns about inefficiency in its price-setting process, Medicare has recently tried to inject market forces for certain health care services. One example of this is durable medical equipment (DME), which includes wheelchairs, oxygen concentrators, and dozens of other health care products.

In July of 2010, the Centers for Medicare and Medicaid Services (CMS) piloted a competitive bidding program $(\mathrm{CBP})$ in nine areas around the country for a subset of DME products. Suppliers were asked to submit price bids for each product and CMS selected the lowest bids, subject to the constraint that the winning suppliers could meet the total demand in these regions. In 2013,

\footnotetext{
${ }^{1}$ For example, prices for physician services are determined by the resource-based relative value scale (RBRVS). These prices are updated annually for more than 10,000 different procedures and vary with the estimated costs to provide each service.
} 
100 regions were added and the process was replicated for an expanded set of products. Before the $\mathrm{CBP}$, Medicare set prices using a fee schedule based on supplier charges to Medicare during the 1980s and increased these amounts annually. These prices were adjusted by state, reflecting geographic price differences that were subject to national floor and ceiling price limits. ${ }^{2}$ There were long-standing concerns that Medicare sometimes paid higher than market rates for various DME items (GAO, 2016).

In 2010 more than 60 percent of Medicare recipients resided in an area where competitive bidding would apply by 2013. CMS selected high-cost and high-volume products to include in the competitive bidding process: the products included in competitive bidding in 2010 or 2013 accounted for more than half of DME expenditures in 2010 just prior to the policy change. We leverage variation across geographic areas and across products in the use of competitive bidding. Medicare's competitive bidding process dramatically reduced spending; most of the reduction was due to lower prices. Our findings reveal that spending on DME products included in competitive bidding fell by 47.2 percent and that this effect persisted over time. ${ }^{3}$

To better understand how the program affected consumers and suppliers, we next focus on a specific DME product - Continuous Positive Airway Pressure (CPAP) machines. The machine is the gold standard of treatment for obstructive sleep apnea (OSA). CPAP machines are a particularly good market to study. First, sleep apnea diagnoses are linked to enrollees in the data. Second, a single product is included in the sample (E0601-RR), so a reduction in quantity demanded cannot be attributed to a rise in substitute products. Third, sleep apnea is a highly prevalent condition, especially among males and the elderly (Senaratna et al., 2017). Sleep apnea is associated with multiple health consequences such as cardiovascular disease and traffic accidents (Marin et al., 2005). In particular, there is growing evidence of a link between sleep apnea and higher risk for

\footnotetext{
${ }^{2}$ Price limits on a per claim basis were derived from the state-level fee-for-service payment. The price ceiling was set at the median of the state-level fee schedule amounts. The price floor was set as 85 percent of the median of the state-level fee schedule amounts. In 2016, CMS started to adjust these fee schedule to incorporate single payment amount from the CBP in non-competitive bidding areas.

${ }^{3}$ We also find evidence for some substitution across DME products, with utilization actually increasing for those DME products not included in competitive bidding. When we account for this substitution, our estimated effects are slightly attenuated, with a 38.2 percent price reduction and a 7.8 percent decline in utilization.
} 
depression, anxiety, and suicidal ideation (Choi et al., 2015; Kaufmann et al., 2017; McCall et al., 2019). Given increasing suicide rates in the US and the disparities by gender and age (Duggan and Scimeca, 2018), proper assessment and treatment for Medicare beneficiaries is increasingly important. Finally, CPAP is relatively large in terms of total Medicare spending on DME products (ranked 6th in 2010). Finally, cost sharing is a substantial burden: $20 \%$ of the rental fee amounts to approximately $\$ 80$ per month over our sample period.

Prior to competitive bidding, Medicare was spending nearly $\$ 200$ million annually on CPAP machines, with rental payments making up most of this amount. Once CMS has made 13 monthly rental payments for a CPAP machine, the Medicare recipient effectively owns it. Our results reveal that competitive bidding reduced the average rental price by $45 \%$ and utilization of this product by 4.3\%. This effect was driven by a decline on both the extensive margin and the intensive margin.

Given the reduction in quantity, the welfare impact of the policy change is unclear. We ask two key questions. First, to what extent are reductions in utilization due to reduced supply? Second, did the program ration care appropriately? To answer the first question, we explore whether the magnitude of the change in utilization differed for Medicare recipients who are dually eligible for the Medicaid program, as this group does not contribute to the cost of their medical care. Theoretically, one would expect a larger quantity reduction for this group since there would be no offsetting demand response. Consistent with this prediction, we estimate a significantly larger reduction in utilization among "dual eligibles." Combining the differential change in duals' outof-pocket costs with the differential change in their utilization, we estimate a demand elasticity of approximately -0.27 . This is very similar to the oft-cited estimate from the RAND Health Insurance Experiment (Manning et al., 1987).

Despite the lowered prices, it is not clear that the CBP rationed CPAP machines appropriately. The combination of lower prices and reduced utilization suggests a potential tradeoff between cost and access. To explore this trade-off, we first show that diagnosis rates were unchanged post-CBP. We next demonstrate that the quantity reductions were concentrated among consumers without a sleep apnea diagnosis. We then construct a measure of clinical appropriateness, similar in spirit 
to Chandra and Staiger (2007). Again, the quantity reductions mostly came from patients with clinical appropriateness below average, and marginal consumers affected by the CBP are those with lower CPAP propensity than average.

While we focus on just one category of Medicare spending, our findings highlight the potential inefficiencies in the program's current methodology for setting prices. The results are especially significant given that many private insurers use Medicare as a benchmark for their own prices. Even with an imperfect bidding process, Medicare's prices for DME products fell by more than 40 percent. Public insurers often use regulated prices, reimbursing providers based on expected costs. Our results highlight that such an approach can lead to inefficiently high spending. In our setting, the savings from introducing competitive bidding were staggering. However, simply setting lower prices is not without trade-offs: quantities also fell. The data indicates that the drop in quantities is due to strategic supplier behavior and is partially offset by a demand response. Yet because the quantity reduction was concentrated in less clinically appropriate patients, a cost-benefit analysis shows that the savings exceed the welfare costs of reduced access.

In concurrent and independent work, Ji (2019) finds similar reductions in price and quantity following the introduction of the CBP. She further models bidding and evaluates the optimality of the government's mechanism. In combination with our results, this suggests that market forces could be a powerful instrument to reduce the high cost of health care in the U.S. generally and in the Medicare program specifically. Our results add to a literature documenting the role of prices in driving healthcare spending (Anderson et al., 2003; Cooper et al., 2019). They also add to growing evidence on the important role of institutions and mechanisms for purchasing health care goods and services. Chandra et al. (2016) argue that the healthcare sector is similar to other industries and subject to standard market forces. Yet while a number of studies contrast public and private provision of insurance in Medicare (Town and Liu, 2003; Curto et al., 2019), less attention has been paid to the mechanisms used to procure health care services within public insurance. The price reductions we measure are more dramatic than those found in earlier studies examining markets for prescription drugs (Duggan and Scott Morton, 2006, 2010; Dranove et al., forthcoming). 
The paper is organized as follows. Section 2 describes the institutional setting and data. Section 3 measures the impact of the $\mathrm{CBP}$ on prices and quantities. Section 4 measures demand elasticities and describes the marginal consumer. Section 5 presents a cost-benefit analysis, and Section 6 concludes.

\section{Setting and Data}

Medicare is a social insurance program that provides health insurance to 62 million elderly and disabled individuals in the U.S. (CMS, 2020a). There are three primary categories of Medicare spending for fee-for-service (FFS) recipients. ${ }^{4}$ Part A covers inpatient care that is provided in hospitals or in skilled nursing facilities along with hospice care (typically provided in one's home). Part B covers outpatient care, physician services, home health care, and durable medical equipment (DME). ${ }^{5}$ The majority of FFS recipients obtain private insurance coverage for prescription drug costs through Medicare Part D, which was created by the 2003 Medicare Prescription Drug, Improvement, and Modernization Act.

We utilize complete Medicare FFS claims data in each year for a random 20 percent sample of the Medicare FFS population. In our main analysis, we restrict attention in each quarter to Medicare beneficiaries who enrolled in FFS Medicare Part B for all three months in the quarter. ${ }^{6}$ Table 1 describes Medicare spending for FFS recipients in both 2010 and 2015. For each year the first column displays the number of individuals with one or more claims for a service and the second lists Medicare spending for that service in the year. For this table, we multiply both the number of recipients and total spending in our data by 5 to estimate national totals.

The final row of Table 1 shows that Medicare spending (normalized to 2015 dollars using the

\footnotetext{
${ }^{4}$ In recent years approximately one-third of Medicare recipients have enrolled in private Medicare Advantage (MA) plans for their coverage. The remaining recipients are enrolled in traditional fee-for-service (FFS) Medicare, through which the government directly reimburses hospitals, physicians, and other health care providers for services delivered to or products obtained by Medicare recipients.

${ }^{5}$ While the vast majority of FFS recipients have one or more Part B claims each year, only about one-in-five have a Part A claim.

${ }^{6}$ When predicting beneficiaries' propensity to use a CPAP device, we require people to be enrolled in FFS Medicare Part B for the full three months in current and previous three quarters so that we can observe all their claims related to sleep apnea.
} 
Consumer Price Index) for those enrolled in FFS Medicare increased from \$376.9 billion to \$407.3 billion from 2010 to 2015; the number of Medicare recipients with one or more Part A and/or Part B FFS claims rose from 32.9 million to 34.5 million over this period. Part B expenditures grew by 11 percent from 2010 to 2015 while Part A expenditures fell by 6 percent, reflecting a shift of home health care services from Part A to Part B. ${ }^{7}$

Table 1: Medicare spending by category

\begin{tabular}{lccccc}
\hline \hline & \multicolumn{2}{c}{$\mathbf{2 0 1 0}$} & & \multicolumn{2}{c}{$\mathbf{2 0 1 5}$} \\
& \multicolumn{2}{c}{ (Before CBP) } & & \multicolumn{2}{c}{ (Last year of our data) } \\
\cline { 2 - 3 } \cline { 5 - 6 } & $\begin{array}{c}\text { Population } \\
\text { (million) }\end{array}$ & $\begin{array}{c}\text { Payment } \\
\text { (billion) }\end{array}$ & & $\begin{array}{c}\text { Population } \\
\text { (million) }\end{array}$ & $\begin{array}{c}\text { Payment } \\
\text { (billion) }\end{array}$ \\
Part A/B & $\mathbf{3 2 . 9}$ & $\mathbf{3 4 1 . 9}$ & & $\mathbf{3 4 . 5}$ & $\mathbf{3 5 0 . 3}$ \\
Part A & $\mathbf{7 . 4}$ & $\mathbf{1 7 3 . 5}$ & & $\mathbf{7 . 0}$ & $\mathbf{1 6 3 . 3}$ \\
- Inpatient Hospital & 6.9 & 132.7 & & 6.6 & 129.8 \\
- Skilled Nursing Facility & 1.5 & 22.2 & & 1.5 & 22.5 \\
- Home Health Agency & 1.5 & 8.0 & & 0 & 0 \\
- Hospice & 0.9 & 10.7 & & 1.0 & 11.0 \\
Part B & $\mathbf{3 2 . 7}$ & $\mathbf{1 6 8 . 4}$ & & $\mathbf{3 4 . 3}$ & $\mathbf{1 8 7 . 0}$ \\
- Physician & 32.4 & 92.7 & & 33.9 & 95.8 \\
- Outpatient & 24.1 & 51.2 & & 25.8 & 64.5 \\
- Home Health Agency & 1.9 & 13.2 & & 3.5 & $18.5^{8}$ \\
- DME & 11.2 & 11.3 & & 10.4 & 8.2 \\
- DME (in CBP) & 6.8 & 5.8 & & 5.7 & 3.3 \\
- DME (not in CBP) & 7.9 & 5.5 & & 7.3 & 5.0 \\
Part D & $\mathbf{1 7 . 5}$ & $\mathbf{3 5 . 0}$ & & $\mathbf{2 3 . 3}$ & $\mathbf{5 7 . 0}$ \\
Part A/B/D Total & $\mathbf{3 3 . 1}$ & $\mathbf{3 7 6 . 9}$ & & $\mathbf{3 4 . 8}$ & $\mathbf{4 0 7 . 3}$ \\
\hline \hline
\end{tabular}

Notes: This table shows the Medicare payments calculated based on 20\% Medicare FFS claim data. We multiplied the total by 5 to get estimates for total Medicare population and spending (normalized to 2015 dollar value based on CPI. ${ }^{9}$ Medicare beneficiaries are restricted to people who have FFS plan. Medicare payments in Part A and B only include the total amount paid by Medicare, excluding cost-sharing paid by beneficiaries or other supplemental insurance plans. Part D payment is calculated based on the amount paid by the Part D plan (among beneficiaries who have an FFS Medicare plan).

\footnotetext{
${ }^{7}$ Part D was the fastest growing component of spending for Medicare FFS recipients during this period. Total Medicare spending was about one-third to one-half higher during this period than implied by our table due to Medicare Advantage, through which an increasing fraction of Medicare recipients obtained their coverage.

${ }^{8}$ Home Health Agency claims are classified into items covered by Medicare Part A or Part B, but always shown as Part B in our data after 2013. According to CMS Program Statistics, the home health agency payment in 2015 has $\$ 6.9$ billion covered by Part A and $\$ 11.3$ billion covered by Part B (CMS, 2015).

${ }^{9}$ https://www.minneapolisfed.org/about-us/monetary-policy/inflation-calculator/ consumer-price-index-1913-
} 
In 2010, Medicare DME spending was $\$ 11.3$ billion and more than 11 million Medicare recipients had one or more DME claims. There are hundreds of DME products, including but not limited to diabetic testing supplies, CPAP devices, oxygen equipment, nebulizers, walkers, wheelchairs, and scooters. Table 2 lists the top 20 (by 2010 spending) DME products. As the table shows, oxygen concentrators accounted for more spending than any other DME product, with $\$ 1.98$ billion in 2010 Medicare expenditures and reimbursement per claim of \$189 in that same year (all 2010 prices and payments are adjusted to 2015 dollar value as in Table 1). The per-claim costs include coinsurance payments by Medicare recipients (or by their secondary insurer). CPAP machines, which are the focus of our study, accounted for \$209.9 million in 2010 Medicare expenditures.

Table 2: Top 20 DME products and CBP lead items in 2010

\begin{tabular}{|c|c|c|c|c|c|c|c|c|}
\hline & \multirow{2}{*}{ HCPCS } & \multirow{2}{*}{ Description (* Lead) } & \multirow{2}{*}{ CBP Round } & \multicolumn{3}{|c|}{ Price } & \multicolumn{2}{|c|}{ Payment (million) } \\
\hline & & & & 2010 FFS & 2015 FFS & 2015 SPA & 2010 & 2015 \\
\hline 1 & E1390-RR & Oxygen concentrator* & $\mathrm{R} 1, \mathrm{R} 2, \mathrm{R} 1 \mathrm{RC}$ & 189.0 & 180.9 & 93.3 & 1977.9 & 1208.7 \\
\hline 2 & A4253-NU-KL & Diabetic test strips, mail & $\mathrm{R} 1, \mathrm{NMO}$ & 35.3 & 34.4 & 10.4 & 995.9 & 148.3 \\
\hline 3 & A4253-NU & Diabetic test strips & & 41.0 & 10.4 & & 551.2 & 166.1 \\
\hline 4 & K0823-NU & Power wheelchair, new & $\mathrm{R} 1^{10}$ & 3964.3 & & & 540.3 & \\
\hline 5 & E0260-RR & Hospital bed* & $\mathrm{R} 1, \mathrm{R} 2, \mathrm{R} 1 \mathrm{RC}$ & 138.1 & 134.4 & 70.6 & 234.8 & 88.1 \\
\hline 6 & E0601-RR & CPAP device* & $\mathrm{R} 1, \mathrm{R} 2, \mathrm{R} 1 \mathrm{RC}$ & 105.2 & 102.4 & 47.0 & 209.9 & 202.3 \\
\hline 7 & B4035 & Enteral feeding supply kit* & $\mathrm{R} 1, \mathrm{R} 2, \mathrm{R} 1 \mathrm{RC}$ & 12.3 & 12.0 & 6.0 & 171.1 & 73.2 \\
\hline 8 & E0431-RR & Portable oxygen system & $\mathrm{R} 1, \mathrm{R} 2, \mathrm{R} 1 \mathrm{RC}$ & 31.3 & 30.4 & 19.4 & 160.8 & 91.3 \\
\hline 9 & A5500 & Diabetic shoe & & 72.6 & 70.6 & & 131.5 & 75.9 \\
\hline 10 & E2402-RR & NPWT pump* & $\mathrm{R} 2, \mathrm{R} 1 \mathrm{RC}$ & 1694.5 & 1648.3 & 817.9 & 131.5 & 97.6 \\
\hline 11 & A4259-KL & Lancets, mail & $\mathrm{R} 1, \mathrm{NMO}$ & 11.5 & 11.1 & 1.6 & 125.5 & 9.6 \\
\hline 12 & A7034-NU & Nasal application device & $\mathrm{R} 1, \mathrm{R} 2, \mathrm{R} 1 \mathrm{RC}$ & 116.2 & 113.0 & 62.8 & 115.9 & 128.3 \\
\hline 13 & B4154 & Enteral formula, metabolic & $\mathrm{R} 1, \mathrm{R} 2, \mathrm{R} 1 \mathrm{RC}$ & 1.3 & 1.3 & 0.7 & 112.2 & 37.8 \\
\hline 14 & E0470-RR & Respiratory assist device & $\mathrm{R} 1, \mathrm{R} 2, \mathrm{R} 1 \mathrm{RC}$ & 238.2 & 231.8 & 117.0 & 99.7 & 84.7 \\
\hline 15 & A7030-NU & CPAP full face mask & $\mathrm{R} 1, \mathrm{R} 2, \mathrm{R} 1 \mathrm{RC}$ & 186.3 & 181.2 & 101.9 & 98.8 & 150.5 \\
\hline 16 & B4150 & Enteral formula, complete & $\mathrm{R} 1, \mathrm{R} 2, \mathrm{R} 1 \mathrm{RC}$ & 0.7 & 0.7 & 0.4 & 92.9 & 39.2 \\
\hline 17 & A5513 & Diabetic shoe, customized & & 44.2 & 43.0 & & 91.2 & 54.1 \\
\hline 18 & E0143-NU & Walker* & $\mathrm{R} 1, \mathrm{R} 2, \mathrm{R} 1 \mathrm{RC}$ & 114.9 & 111.7 & 53.7 & 91.1 & 52.1 \\
\hline 19 & A5512 & Diabetic shoe, direct formed & & 29.6 & 28.8 & & 87.9 & 50.2 \\
\hline 20 & E0748-NU & Osteogenesis stimulator & & 4463.7 & 4342.1 & & 86.5 & 92.5 \\
\hline 21 & E0277-RR & Pressure-reducing mattress* & $\mathrm{R} 1, \mathrm{R} 2, \mathrm{R} 1 \mathrm{RC}$ & 681.8 & 663.2 & 239.3 & 81.8 & 16.3 \\
\hline 33 & E0570-RR & Nebulizer* & $\mathrm{R} 1 \mathrm{RC}$ & 18.4 & 17.9 & 10.2 & 55.0 & 42.3 \\
\hline 36 & E0163-NU & Commode chair* & $\mathrm{R} 1 \mathrm{RC}$ & 122.4 & 119.1 & 63.8 & 47.1 & 26.6 \\
\hline 43 & E0784-RR & External infusion pump* & $\mathrm{R} 1 \mathrm{RC}$ & 478.3 & 465.2 & 380.2 & 39.5 & 51.1 \\
\hline 61 & E0630-RR & Patient lift* & $\mathrm{R} 1 \mathrm{RC}$ & 111.5 & 108.5 & 63.3 & 27.5 & 21.4 \\
\hline 63 & A4595 & TENS supplies* & $\mathrm{R} 1 \mathrm{RC}$ & 32.8 & 32.0 & 15.2 & 26.9 & 9.6 \\
\hline 247 & K0823-RR & Power wheelchair, rent* & $\mathrm{R} 1, \mathrm{R} 2, \mathrm{R} 1 \mathrm{RC}$ & 396.4 & 578.5 & 297.6 & 2.0 & 56.2 \\
\hline
\end{tabular}

Notes: This table shows the price and payment in 2010 for the top 20 DME products (based on 2010 payment) and lead items in the CBP (labelled with *). Products are identified based on HCPCS code with key modifier, ie. "NU", "RR", "UE", "MS", "KL", "BA", "KC". Prices are the average across states or competitive bidding areas. Payments are calculated based on 20\% Medicare FFS claim data. We multiplied the total by 5 to get estimates for total spending. Payments are Medicare allowed amount, which includes both total amount paid by Medicare and cost-sharing paid by beneficiaries or other supplemental insurance plans. All prices and payments are normalized to 2015 dollar value based on CPI (same as in Table 1). 
In addition to creating Medicare Part D, the 2003 Medicare Prescription Drug, Improvement, and Modernization Act established the framework for competitive bidding for certain DME products. The program officially started in January 2011 (with a bidding process in 2009) in nine Round 1 competitive bidding areas (CBAs) and was then expanded to another 100 CBAs in Round 2 in July 2013. ${ }^{11}$ Each round lasted for three years, and so there was a "Round 1 Recompete" that started in January 2014 in the same nine Round 1 CBAs. CBAs were selected by CMS mainly based on core based statistical areas (CBSAs) with larger populations, Medicare DME spending (per recipient), and suppliers per recipient. ${ }^{12}$

Table 3 provides summary statistics for Round 1 CBAs, Round 2 CBAs, and the remaining 860 CBSAs. The most notable difference is that the Round 1 and Round 2 CBAs on average had substantially more Medicare recipients than in other CBSAs. As a result, more than 60 percent of Medicare FFS recipients (based on 2010 enrollment and residence) lived in an area that had competitive bidding in effect by July 2013. Additionally, average spending per recipient was significantly higher in 2010 in the geographic areas that were selected for competitive bidding, yet average spending for DME products and the share of recipients with DME claims (included in the CBP) did not differ much between CBAs and other CBSAs.

Across different rounds of the CBP, CMS divided DME into 14 categories: mail-order diabetic testing supplies, enteral nutrients equipment, hospital beds, supporting surfaces, wheelchairs, walkers, oxygen equipment, CPAP devices, negative pressure wound therapy (NPWT) pumps, commode chairs, external infusion pumps, patient lifts, transcutanesous electrical nerve stimulators (TENS), and nebulizers. ${ }^{13}$ The majority of these categories, namely diabetic testing supplies, en-

\footnotetext{
${ }^{10}$ Purchasing option was included in Round 1 , but only rental option in later rounds.

${ }^{11}$ Before the official start of the CBP in 2011, CMS implemented Competitive Bidding Demonstration for DME, prosthetics, orthotics, and supplies, during 1999-2002 in Polk County, Florida and San Antonio, Texas. Three rounds of bidding in the two sites showed price reduction but little impact on utilization. More detailed evaluation is reported in (Hoerger et al., 2003). Then in 2007, CMS conducted the Round 1 CBP and awarded contracts effective July 1, 2008, to suppliers. The Medicare Improvements for Patients and Providers Act (MIPPA) of 2008, however, terminated the Round 1 contracts on July 15, 2008, and required CMS to repeat the competition in 2009 (GAO, 2016).

${ }^{12}$ Beyond CBAs we follow similar steps as CMS, grouping zipcodes into core based statistical areas (CBSAs).

${ }^{13}$ In the CBP, included products are grouped into different categories. These categories are slightly different across rounds, for example oxygen equipment, CPAP, and nebulizers were grouped together as respiratory equipment in the R1 Recompete, but separately in all other rounds. The grouping we used in this paper is mostly based on Round 2021 which also selects the lead item within each category.
} 
Table 3: Summary Statistics Across Geographic Areas

\begin{tabular}{lccc}
\hline \hline & $\begin{array}{c}\text { Non-CBA } \\
(\mathbf{N = 8 6 0})\end{array}$ & $\begin{array}{c}\text { R1 CBA } \\
(\mathbf{N = 9})\end{array}$ & $\begin{array}{c}\text { R2 CBA } \\
(\mathbf{N = 1 0 0})\end{array}$ \\
\cline { 2 - 4 } \# MCR FFS Population & 2,979 & 58,460 & 36,552 \\
Age & 70.7 & 71.1 & 71.1 \\
Male & 0.45 & 0.45 & 0.45 \\
SSDI & 0.20 & 0.18 & 0.18 \\
Dual Eligible & 0.18 & 0.20 & 0.19 \\
Average MCR Payment & 7,558 & 9,465 & 8,717 \\
Average MCR DME Payment & 285.6 & 302.0 & 255.1 \\
Has DME Claim & 0.29 & 0.28 & 0.26 \\
Has CBP DME Claim & 0.18 & 0.18 & 0.16 \\
\hline \hline
\end{tabular}

Notes: This table presents summary statistics from Medicare 20\% FFS data in 2010. Geographic area is defined as core based statistical areas (CBSAs), which are the basis for defining CBAs. For a few cases that are not perfectly matched, we keep CBSAs that consists the majority of each CBA, and drop small areas that are left outside CBAs. Medicare FFS population counts beneficiaries that had no HMO coverage over the 12 months. Average Medicare payment per beneficiary includes only Medicare payment in Part A and B, but not deductible, coinsurance, etc. All summary statistics except average population are weighted by Medicare FFS population.

teral nutrients equipment, hospital beds, supporting surfaces, wheelchairs, walkers, oxygen equipment, and CPAP devices were included in competitive bidding from the first round. NPWT pumps were then included in Round 2 (along with Round 1 Recompete in Round 1 areas). ${ }^{14}$

Within each product category, there is one lead item assigned by CMS based on the highest total allowed charges nationwide together with its related accessories. ${ }^{15}$ For example, rental payments for oxygen concentrators (HCPCS code E1390-RR) accounted for 83.2\% of the payment in 2010 in the category of oxygen equipment, while other types of oxygen system equipment (i.e. portable, stationary, liquid, gaseous oxygen systems) and contents accounted for the remainder. As for the CPAP category, rental payments for the device (HCPCS code E0601-RR) accounted for 24.0\% of category payments in 2010, while its accessories such as nasal interface, full face mask, and

\footnotetext{
${ }^{14}$ External infusion pumps, commode chairs, patient lifts, TENS, and nebulizers were included in Round 1 Recompete (and a second round recompete, which is outside our sample).

${ }^{15}$ External infusion pumps will not be included in 2021 and therefore do not have a lead item selected. To be consistent with other categories, we also select the top item by 2010 Medicare payment, the external ambulatory infusion pump for insulin (HCPCS code E0784-RR), as the lead item of this product category.
} 
exhalation port accounted for $13.2 \%$ to less than $1 \%$. For the other categories, the lead item accounted for between $27.6 \%$ and $91.5 \%$ of the total payment within the category in 2010 .

The fourth column of Table 2 shows, for each of the top-selling DME products, whether it was included in Round 1 (R1), Round 2 (R2), or the Round 1 Recompete (R1RC). The next three columns list the average 2010 FFS price, the average 2015 FFS price, and the average 2015 price in CBAs. With just one exception (diabetic test strips, which experienced a significant price drop), the 2015 FFS price is only slightly below the 2010 FFS price. ${ }^{16}$ For products included in competitive bidding, the 2015 FFS price represented the average price that prevailed outside of the 109 CBAs (an average across 53 state FFS prices published by CMS). The next column lists the average price for each product in competitive bidding areas in 2015. In almost every case, the average price in competitive bidding areas is substantially lower than the FFS price in that same year. For CPAP devices, the average price in competitive bidding areas was 54 percent lower (\$47.0 vs. \$102.4). Our study will exploit variation over time and across space to explore the extent to which changes in prices and quantities were driven by the CBP.

In our empirical analysis below, we initially consider the lead item in each of the $12 \mathrm{DME}$ categories when estimating the effect of competitive bidding on the price and total quantity of each product along with the market structure (e.g. the number of suppliers or the HHI). We next focus on the effect of competitive bidding on just CPAP devices. These devices are used to treat obstructive sleep apnea, which is a potentially serious sleep disorder in which breathing repeatedly stops and starts during sleep. The American Academy of Sleep Medicine (AASM) recommends CPAP as both the first-line and the gold-standard treatment for obstructive sleep apnea (Ramar et al., 2015). Medicare beneficiaries rent CPAP devices. After paying rental payments for CPAP devices for 13 months, Medicare patient own the device. ${ }^{17}$

\footnotetext{
${ }^{16}$ Most DME products were excluded from competitive bidding, though the products that CMS selected tended to have significantly higher spending and volume. CMS revised fee schedule for non-mail order diabetic testing supplies to be equal to mail orders in 2012 (https://www.cms.gov/Medicare/Medicare-Fee-for-Service-Payment/ DMEPOSFeeSched)

${ }^{17}$ CPAP is listed within CMS's "capped rental DME" category. In this setting, Medicare pays a monthly rental fee that is capped at 13 consecutive months. Within the 13 months, months 1-3 are paid at the published fee schedule rental rate, and months $4-13$ are paid at $75 \%$ of the published rate.
} 
A primary goal of the CBP was to induce market-based prices that would replace the current fee-for-service prices for home medical equipment. At the same time, Congress passed legislation creating the Medicare Part D program. That program successfully leveraged market mechanisms to reduce pharmaceutical prices (Duggan and Scott Morton, 2010). A natural question is whether similar mechanisms can have a similar impact for other goods and services purchased by the Medicare program. ${ }^{18}$ Yet there are important design issues even for DME products within the CBP.

Previous research has criticized three key features of the CBP: the median price auction and non-binding bids. Under the approach used by CMS, a supplier does not have a financial incentive to truthfully bid its reservation price (Merlob et al., 2012; Cramton et al., 2015). If suppliers did bid their costs, the median price would then be set below some winning bidders' costs: the medianprice auction is not ex-post individually rational. Furthermore, "winning" the auction does not guarantee that a firm becomes a Medicare supplier. While winning the auction earns a firm the option of signing a supply contract, bids are not binding. Cramton et al. (2015) points out that this feature generates the incentive for "suicide" (low) bids to preserve that option. In practice, this means that CMS could choose a price that is just high enough so that the market does not collapse.

Finally, the competitive bidding mechanism could affect market structure and prices in future periods. In the CPAP market we study, there are three major manufacturers (ResMed, Philips Respironics, and Fisher \& Paykel) capturing more than $80 \%$ of the total market share. Suppliers of the renting services are DME distributors, mostly regional and local providers together with a few national providers such as Lincare and Apria. ${ }^{19}$ Appendix Figure A1 shows that market concentration grew post-CBP: the HHI increased by 0.05 (or 500) points in the average CBA. This is primarily due to two factors: small local firms exiting the market and large national players growing. A natural concern is that the CBP could lead to increased consolidation and higher prices in the future. ${ }^{20}$

\footnotetext{
${ }^{18}$ For example, it may be difficult to auction off health care services such as medical procedures that may be of differing quality across providers.

${ }^{19}$ Lincare is owned by a multinational chemical company. Apria is privately held and managed by affiliates of the Blackstone Group.

${ }^{20}$ However, we note that the reduction in suppliers is a policy choice: only about one-third of the bidding suppliers were awarded CBP contracts (GAO, 2012). Despite rental services, suppliers also provide and get paid for the replace-
} 
Both the sign and the magnitude of the effect of Medicare's CBP on quantity are theoretically ambiguous. On the one hand, the lower price for DME products along with the termination of some supplier contracts could reduce the total quantity supplied. On the other hand, since most Medicare recipients share in the cost of their medical care, the lower price could increase the total quantity demanded. Therefore, the equilibrium impact of competitive bidding on total quantity is ultimately an empirical question.

\section{The Impact of Competitive Bidding on Prices and Quantities}

\subsection{All Product Categories}

In this section, we evaluate the impact of Medicare's CBP on prices, quantities, and Medicare spending. We initially focus on the twelve lead items, excluding two categories of DME products, diabetic testing supplies and wheelchairs. ${ }^{21}$ As denoted with an asterisk in Table 2, the lead items vary substantially in price and total payment. For example, the top product - oxygen concentrators - accounted for $\$ 1.98$ billion in Medicare spending in 2010 with a monthly rental price that year of \$189.0. TENS supplies, however, only cost \$32.8 and had just \$26.9 million in total spending that year.

We leverage variation with respect to time, product, and geographic area in the use of competitive bidding. We include R1 CBAs where the CBP started in 2011Q1, R2 CBAs where the CBP started in 2013Q3, and geographic areas that have never been included in the CBP as controls. We consider the period from the first quarter of 2009 through the fourth quarter of 2015, which gives us at least two full years before competitive bidding was launched in any CBA and at least two full

ment of related supplies under frequency restrictions that are set by CMS. With the start of the CBP, new Medicare patients could only get CPAP from suppliers with a DME contract. Suppliers not awarded contracts could elect to become grandfather suppliers to continue providing CPAP for their existing patients (e.g. those who were 4 months into the 13 months needed to own) but could not provide DME products to new patients.

${ }^{21}$ We do this because 1 ) only mail-ordered diabetic testing supplies were included in the CBP and this became nationwide in $2013 ; 2$ ) the price for non-mail-ordered diabetic testing supplies also went down and there could therefore be substitution with mail-order items that confound the analysis; and 3) the purchasing option of the power wheelchair changes during this time period and differs across CBAs and non-CBAs, which may complicate the analysis. 
years after launch in each area. To study the timing of the effect, we plot the estimated coefficients on indicators for the number of quarters since the CBP. More precisely, let $E_{p s}$ be the quarter in which product $p$ in geographic area $s$ enters the CBP. Let $D_{p s t}^{l}=1\left(t-E_{p s}=l\right)$ be an indicator that is equal to one if and only if product $p$ in geographic area $s$ is $l$ quarters from the start of the CBP at time $t .^{22}$ Then our event study specification is:

$$
Y_{p s t}=\sum_{l=-20}^{9} \beta^{l} D_{p s t}^{l}+\phi_{p t}+\sigma_{s t}+\theta_{p s}+\varepsilon_{p s t}
$$

in which we include product fixed effects, CBSA fixed effects, year-quarter fixed effects, and their double interaction: $\phi_{p t}$ are product by year-quarter fixed effects, $\sigma_{s t}$ are CBSA by year-quarter fixed effects, and $\theta_{p s}$ are product by CBSA fixed effects. ${ }^{23}$ We plot the $\beta^{l}$ coefficients for all time periods. We weight each observation by the number of claims in that geographic area for that product in 2010, and cluster standard errors by geographic area.

Figure 1 plots the coefficients on the lag and lead indicators of competitive bidding for key outcome variables of interest: prices, quantities (total number of product/service counts per 1000 Medicare FFS recipients ${ }^{24}$ ), and spending (total Medicare allowed amount per 1000 Medicare FFS recipients). We estimate specifications in logs to account for the considerable differences in baseline prices, quantity, and spending across the 12 products. ${ }^{25}$ Panel A of Figure 1 shows that prices fall dramatically in the post-period. Appendix Table A1 shows that post-CBP, prices fall by an average of $41.8 \% .{ }^{26}$ Similarly, Panel B of Figure 1 shows that quantity is flat before competitive

\footnotetext{
${ }^{22} \mathrm{We}$ allow for 20 lags and 9 leads, excluding periods that are 9 quarters after the CBP (when there is only Round 1 CBAs in the sample which entered into Round 1 Recompete and experienced further changes in price and quantity). Furthermore, we set $\beta^{-1}=0$.

${ }^{23} \mathrm{We}$ can do this because different products are added in the CBP at different time.

${ }^{24}$ Since DME is covered by Medicare Part B, we restrict our sample to Medicare recipients who had full FFS Part $\mathrm{B}$ coverage in each quarter. We aggregate quantity and payment for DME among these beneficiaries and use this population as denominator.

${ }^{25} \mathrm{~A}$ minority of product by geographic area by quarter cells (21\%) have zero claims and therefore are missing $\log$ price, $\log$ quantity and log payment. This is mostly driven by small geographic areas not included in the CBP. Given that we weight by the number of claims in each area for each product in the pre-CBP period, this has a relatively small impact. In a series of robustness checks, we exclude areas that are not in the CBP from the analysis sample. The results are very similar.

${ }^{26}$ The -0.46 coefficient in the initial quarter implies a $37 \%\left(e^{-0.46}-1=-0.37\right)$ decrease in price, which drops further to $45 \%$ four quarters after the CBP. The gradual decline in price could be due to a grandfather clause that enabled some patients to continue rental services from their old DME suppliers at the original price.
} 


\section{Figure 1: The Impact of Competitive Bidding on Lead Item Prices and Quantities}
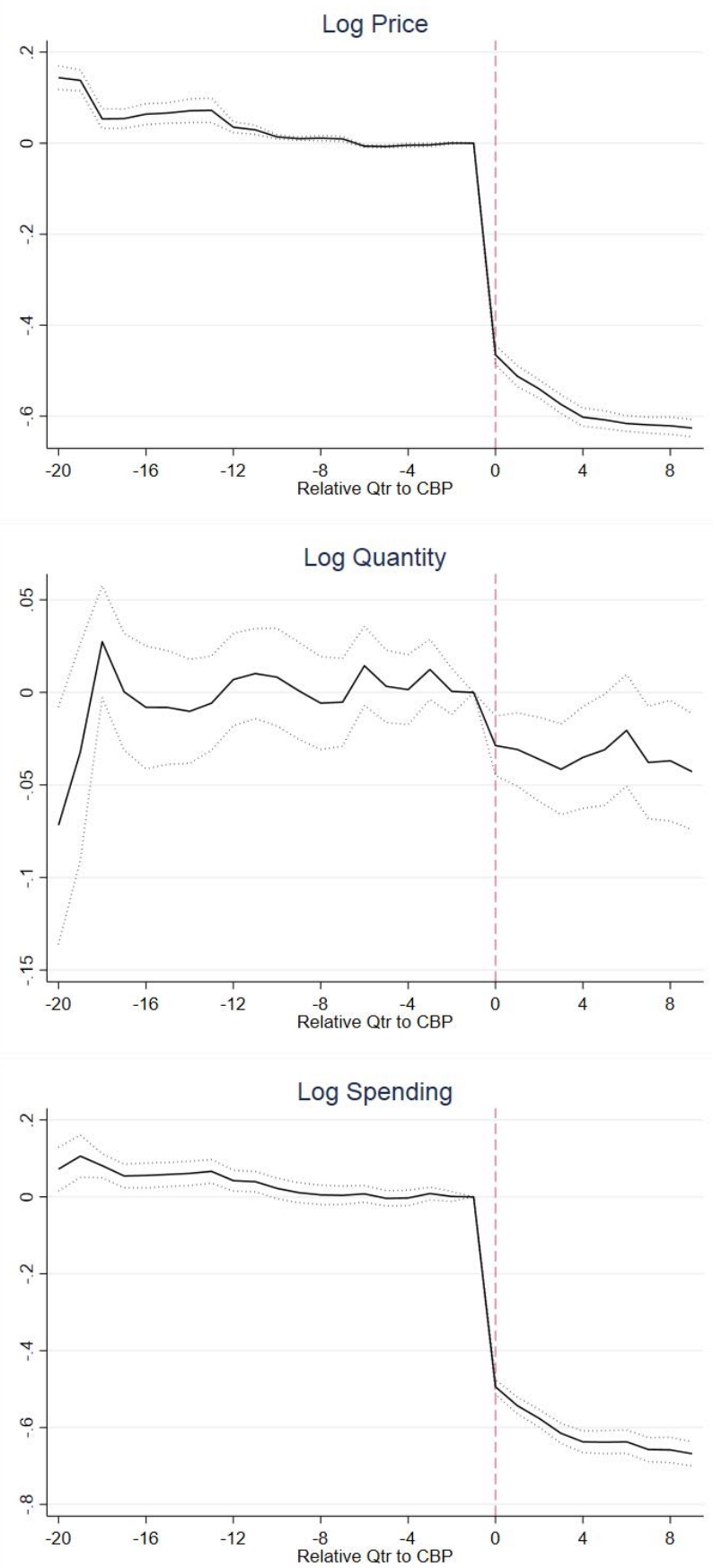

Notes: These figures plot the coefficient estimated using event study regression (1) among the pooled sample of 12 lead items. The observation is at product by CBSA by year-quarter level. Outcome variables include price, quantity (total number of product counts per 1000 Medicare FFS recipients), and spending (total Medicare allowed amount per 1000 Medicare FFS recipients), all in log terms. The solid line is point estimates for the effect of quarter pre/post-CBP and the dotted lines are the 95 percent confidence interval for those coefficients, based upon standard errors that are clustered at the CBSA level. All regressions include product fixed effects, CBSA fixed effects, year-quarter fixed effects, and their double interaction. All regressions are weighted by the number of claims in each CBSA for each product in 2010 . 
bidding, falls immediately when competitive bidding is introduced, declines slightly further over time, and on average dropped 9.3\% after the CBP as shown in Appendix Table A1. Finally, Panel $\mathrm{C}$ of Figure 1 presents the net effect of competitive bidding on spending per enrollee. The fall in total spending is visually (and economically) substantial. Appendix Table A1 shows that spending falls by an average of $47.2 \%$ after the CBP.

In Appendix Table A2, we present several robustness checks. Columns 1 and 2 restrict the sample to only the 9 round 1 and 100 round 2 competitive bidding areas; the results are similar. Columns 3 and 4 restrict the sample to large non-CBAs (>9000 Medicare FFS population in 2010) along with round 1 and 2 competitive bidding areas. Again, the results are very similar. Columns 5 and 6 add a state-by-post-CBP indicator, which turns on when any area in the state has been included in the CBP to control for the effects of changes over time in state-level policies, including Medicaid. Again, the results are similar. Columns 7 and 8 restrict attention to Medicare FFS recipients who are enrolled in the program during our entire sample period; the results are once again quite consistent with our baseline results.

Finally, Appendix Table A3 summarizes the results from separate specifications for each of the lead items within each category. The range of the average price drop is $12 \%$ to $51 \%$. Average quantity falls for all 12 items (and this is statistically significant among nine), and the reductions range from $2 \%$ to $90 \%$. In the next section we look more closely at this results, focusing exclusively on CPAP machines.

Appendix Table A1 Panel B estimates the same specifications at the category (rather than product) level. ${ }^{27}$ These specifications allow for substitution across products within a category. As expected, the impact is slightly attenuated: prices fall by $38.2 \%$, while quantities fall by $7.8 \%$ once we allow for within-category substitution. The program, viewed from this level, still substantially lowers program expenditures: Medicare reimbursement falls by an average of $43.0 \%$.

\footnotetext{
${ }^{27}$ We aggregate total payment and quantity (the number of items or services provided) within each category and calculate the average price per item.
} 


\subsection{CPAP Machines}

Figure 2 replicates the analysis in Figure 1, restricting attention to CPAP machines. ${ }^{28}$ Similar to the aggregate analysis, both the average price of CPAP machines and spending on these products fall significantly upon the introduction of competitive bidding. As this figure shows, average quantities also decline.

In Table 4, we estimate the relative magnitudes of the impact of competitive bidding. We use 2010 FFS population weights, and include both MSA \& CBSAs. The estimating equation is given by:

$$
Y_{s t}=\beta_{1} \cdot C B P_{s t}+\sigma_{s}+\theta_{t}+\varepsilon_{s t}
$$

where the dependent variables are (the log of) price, quantity, the number of (new) beneficiaries with one or more CPAP claims, and Medicare reimbursement (all denominated by 1000 Medicare FFS recipients except price) for CPAP in geographic area $s$ during year-quarter $t$. The main variable of interest is the treatment indicator $C B P_{s t}$ which is set equal to 1 when CPAP is included in the $\mathrm{CBP}$ in geographic area $s$ during year-quarter $t$ and otherwise equal to 0 . In all regressions, we include geographic $\sigma_{S}$ and quarter-by-year $\theta_{t}$ fixed effects.

Table 4 presents the results. Because we are looking at a single product, we do not need to distinguish between the lead item and the rest-of-category demand. Again, the patterns in the results are striking. Competitive bidding leads to a $44.8 \%\left(e^{0.594}-1=-0.448\right)$ reduction in the average price of the rental. Given a pre-competitive bidding mean of $\$ 79 /$ month in 2010 , this represents a $\$ 35 /$ month price reduction (or $\$ 7$ in OOPC to consumers facing 20 percent cost sharing per claim). Again, quantities also fall by an average of about $4.3 \%\left(e^{0.0442}-1=0.0432\right)$, regardless of the measure of quantity; the quantity reductions are due to both new beneficiaries and existing consumers. On net, average Medicare spending for CPAP devices falls by $47.2 \%$

\footnotetext{
${ }^{28}$ Price, quantity (per 1000 Medicare FFS recipients) and spending (per 1000 Medicare FFS recipients) are still in $\log$ terms to show changes in percentages. Only $1.4 \%$ of the geographic by quarter cells have zero claims for CPAP and thus have missing price, log quantity and payments. We also weighted geographic area by it size, measured as Medicare FFS population in 2010 (based FFS Part B months and counting people with 6-month coverage as 0.5).
} 
Figure 2: The Impact of Competitive Bidding on CPAP Prices and Quantities
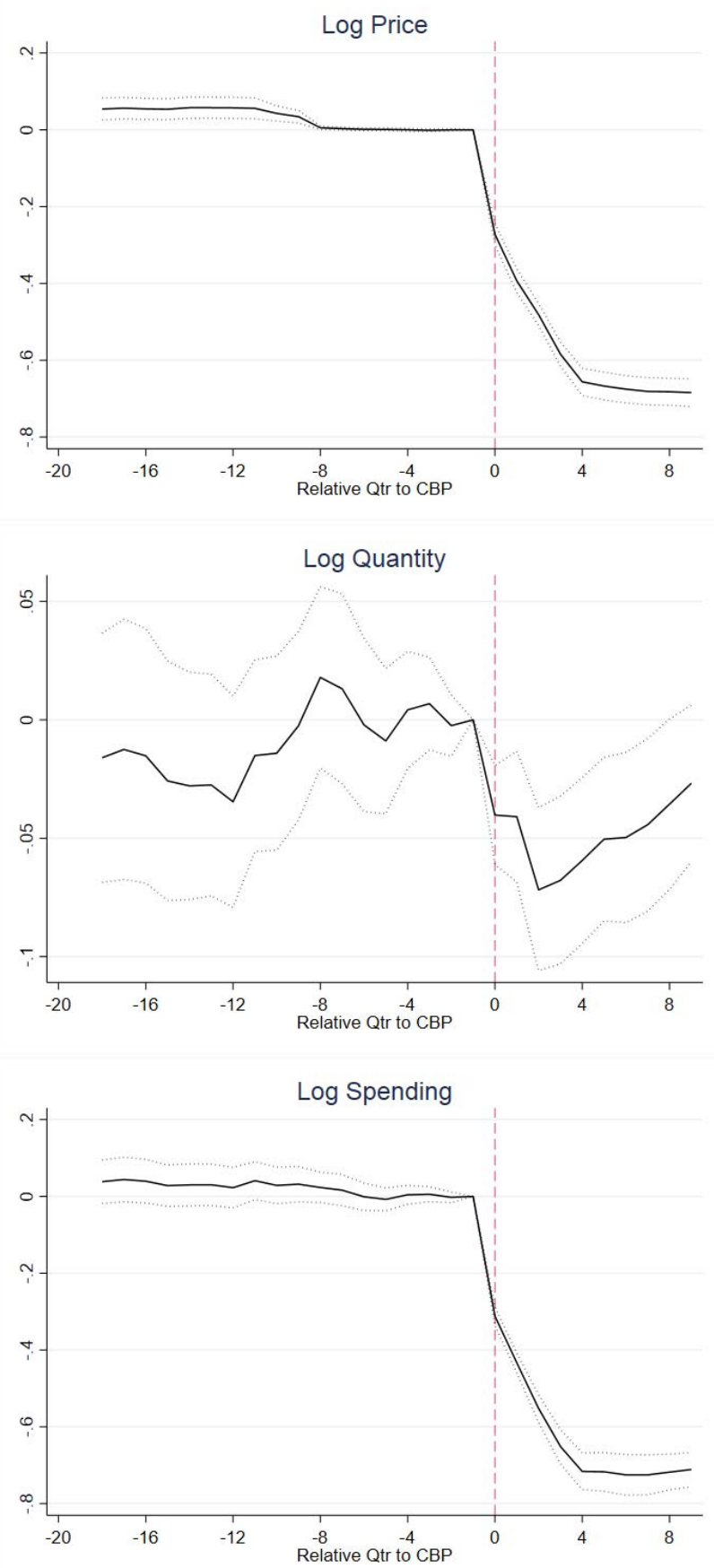

Notes: These figures replicate Figure 1 for CPAP only. The observation is at CBSA by year-quarter level. Outcome variables include price, quantity (total number of product/service counts per 1000 Medicare FFS recipients), and spending (total Medicare allowed amount per 1000 Medicare FFS recipients), all in log terms. The solid lines are point estimates for the effect of quarter pre/post-CBP and the dotted lines are the 95 percent confidence interval for those coefficients, based upon standard errors that are clustered at CBSA level. All regressions include CBSA fixed effects and year-quarter fixed effects. All regressions are weighted by Medicare FFS population in 2010. 
Table 4: The Impact of Competitive Bidding on CPAP Prices and Quantities

\begin{tabular}{lccccc}
\hline \hline & $(1)$ & $(2)$ & $(3)$ & $(4)$ & $(5)$ \\
& Log & Log & Log & Log New & Log \\
& Price & Quantity & Beneficiaries & Beneficiaries & Spending \\
\hline \multirow{2}{*}{1 (Competitive Bidding) } & $-0.594 * * *$ & $-0.0442^{* * *}$ & $-0.0439 * * *$ & $-0.0437 * * *$ & $-0.638^{* * *}$ \\
& $(0.0150)$ & $(0.0163)$ & $(0.0151)$ & $(0.0126)$ & $(0.0193)$ \\
Mean & 71.33 & 20.45 & 8.300 & 2.326 & 1466 \\
N & 26,762 & 26,762 & 26,762 & 25,120 & 26,762 \\
Year-Quarter FE & Yes & Yes & Yes & Yes & Yes \\
CBSA FE & Yes & Yes & Yes & Yes & Yes \\
\hline \hline
\end{tabular}

Notes: This table presents the results of regression analysis for the effect of the CBP on price and quantity of CPAP. The observation is at CBSA by year-quarter level. Outcome variables include price, quantity, number of (new) beneficiaries, and total spending, all denominated by one thousand Medicare FFS beneficiaries except price, and all in log terms (the mean of dependant variable shown is in level terms). All regressions include CBSA fixed effects and year-quarter fixed effects. All regressions are weighted by Medicare FFS population in 2010. Standard errors are clustered at CBSA level. Significance levels: $* 10 \%, * * 5 \%, * * * 1 \%$.

$\left(e^{0.638}-1=-0.472\right)$ following the introduction of competitive bidding.

Table 5 documents other potential margins of adjustment. One potential concern is that the reduction in utilization is partly reflecting a deferral of necessary care among Medicare recipients. Column 1 shows that the incidence of obstructive sleep apnea (or OSA, as measured by number of patients newly diagnosed with OSA per 1k Medicare population) actually goes up after the introduction of competitive bidding, suggesting that if anything more patients are receiving inperson care for this diagnosis. Appendix Figure A2 shows that this is not attributable to differential trends in areas that introduced competitive bidding. The result is similar if we include all types of sleep apnea (SA) beyond OSA. Column 2 shows that total Medicare FFS spending (not including DME) for patients with an OSA diagnosis falls by $4.0 \%$ post-CBP along with a $25.7 \%$ reduction in DME spending in Column 3, suggesting that there is no substitution to other types of care or deterioration of people's health.

Taken together, the results in this section demonstrate that the introduction of competitive bidding led to a sharp reduction in the price of DME products and a reduction in the utilization of these products as well. The effects were similar when considering all lead items in the $12 \mathrm{DME}$ categories or when focusing exclusively on CPAP devices. In both cases, we estimate that com- 
Table 5: Obstructive Sleep Apnea

\begin{tabular}{lccc}
\hline \hline & $(1)$ & $(2)$ & $(3)$ \\
& Log & Log MCR & Log MCR \\
& Diagnosis & A/B Spending & DME Spending \\
\hline 1(Competitive Bidding) & $0.0407 * * *$ & $-0.0412^{* * *}$ & $-0.297 * * *$ \\
& $(0.0151)$ & $(0.00804)$ & $(0.0133)$ \\
& & & \\
Mean & 3.870 & 3977 & 249.1 \\
$\mathrm{~N}$ & 26,127 & 27,013 & 26,901 \\
Year-Quarter FE & Yes & Yes & Yes \\
CBSA FE & Yes & Yes & Yes \\
\hline \hline
\end{tabular}

Notes: This table presents the changes in the incidence of obstructive sleep apnea after the introduction of the CBP, as well as the Medicare spending of the diagnosed OSA patients. The observation is at CBSA by year-quarter level. Outcome variables are the number of patients newly diagnosed with OSA (primary diagnosis recorded as ICD-9 code 327.23 or ICD-10 code G47.33 in inpatient, outpatient or physician carrier table) among one thousand Medicare FFS population, average Medicare Part A/B spending (non-DME), and DME spending among OSA-diagnosed patients. All regressions are weighted by Medicare FFS population in 2010. Standard errors are clustered at CBSA level. Significance levels: *10\%, **5\%,***1\%.

petitive bidding substantially lowered Medicare spending. In the next section, we investigate the mechanisms driving these changes and explore heterogeneity in both the price and utilization effects.

\section{Mechanisms and Heterogeneity}

\subsection{Heterogeneity}

In this section, we focus on CPAP machines to (a) decompose the contribution of supply and demand to the changes summarized above and (b) measure allocative efficiency given the change in utilization. We do this by (a) focusing on heterogeneity by dual status and (b) clinical appropriateness. Figure 3 plots the differences in our event study framework between those Medicare recipients who are dually eligible for the Medicaid program, and all other Medicaid recipients. The figure also shows the trajectory of prices and utilization before and after the introduction of the CBP for beneficiaries with and without a sleep apnea diagnosis. 
Theoretically, we expect a different quantity effect for dual eligibles. Duals were fully insulated from any price changes before and after the policy change due to their secondary coverage from Medicaid. In contrast, there was a reduction in out-of-pocket price for non-duals as a result of the CBP, as the allowed amounts for Medicare declined. All else equal, this would lead to an increase in their utilization of CPAP machines.

As panel A of Figure 3 shows, the reduction in the total price is essentially identical for duals and non-duals. However, we observe a substantial reduction in utilization among duals (who had no offsetting effect of a lower out-of-pocket price) while the utilization remains relatively constant for non-duals. This strongly suggests that the differential changes in out-of-pocket prices were responsible for the relative decrease in quantity among those dually eligible for Medicaid. Perhaps not surprisingly, quantity declines more for those Medicare recipients without a sleep apnea diagnosis, suggesting that the patients with more severe sleep apnea continued to use CPAP devices.

Table 6 presents treatment effect estimates for different groups of consumers categorized by demographics and health status. The results in Table 6 are quite consistent with the differences implied by Figure 3. Quantities fell by significantly more among dual eligibles and among those without a sleep apnea diagnosis. The point estimates also suggest a larger reduction among men than among women, though the difference is not statistically significant. We explore these differences further in the next section, along with the allocative efficiency of the changes in utilization.

\subsection{Separating Supply and Demand}

We observe very different utilization patterns between those Medicare recipients with and without Medicaid coverage (duals and non-duals, respectively). We will use this heterogeneity to separate the impact of the CBP into its supply-side and demand-side components.

How does a change in the administrative price affect equilibrium outcomes? First, due to the rules of the Medicare program, a price drop reduces out-of-pocket costs to consumers (by $20 \%$ of the change in price). The price reduction is passed on to non-duals in the form of lower cost sharing, which could increase in the quantity demanded. Second, a price reduction could also lead 
Figure 3: The Impact of Competitive Bidding on CPAP Prices and Quantities by Subgroups

(a) Dual vs. Non-Dual
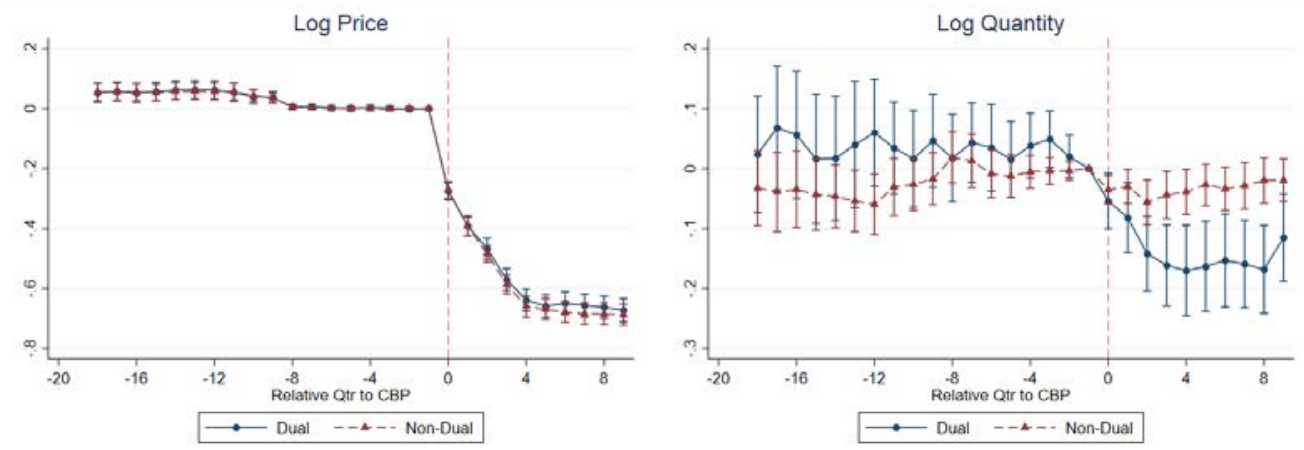

(b) SA vs. No SA
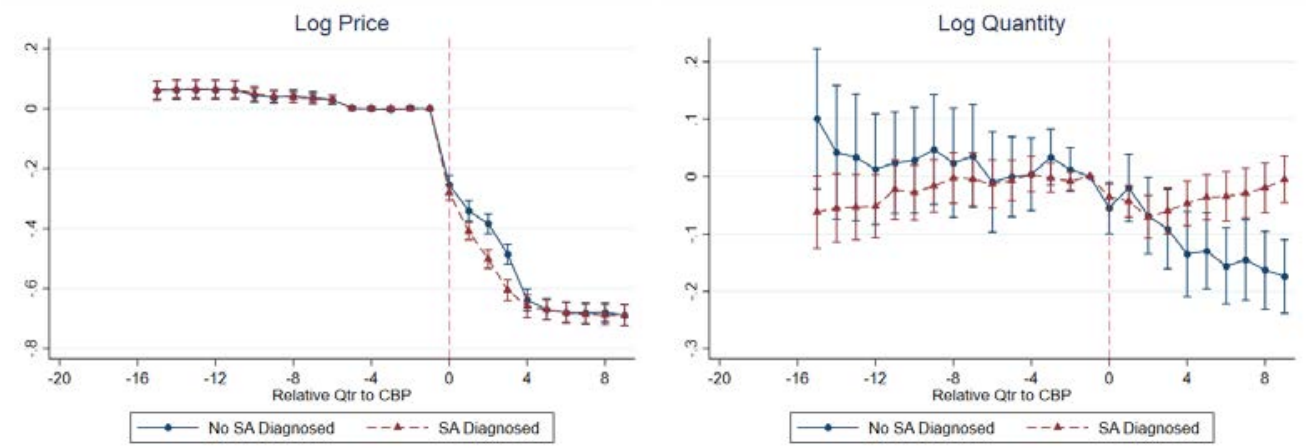

(c) OSA vs. No OSA
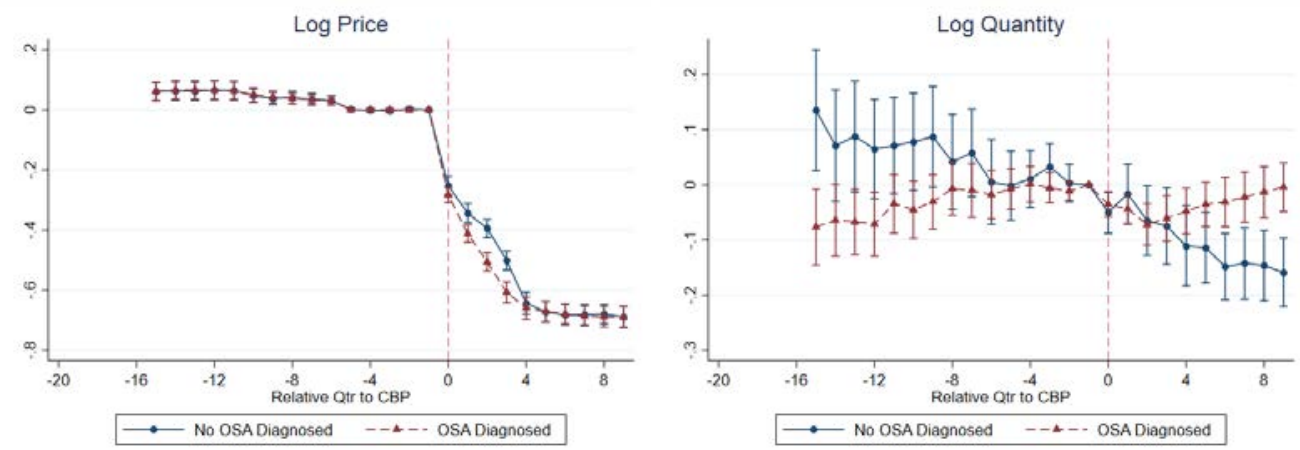

Notes: These figures plot event study coefficients of relative years interacting with group dummies. The observation is at CBSA by year-quarter by subgroup level. Panel A groups sample to duals vs nonduals. Panel B and C define subgroups as those diagnosed with either SA (primary diagnosis recorded as ICD-9 code 327.2 or ICD-10 code G47.3 in an inpatient, outpatient, or physician carrier table) or OSA (primary diagnosis recorded as ICD-9 code 327.23 or ICD-10 code G47.33) in the previous year, restricting to patients who remained enrolled in Medicare for the current and previous 3 quarters to get full information on their diagnosis (sample period starts from 2009Q4). Outcome variables include price and quantity (total number of product/service counts per one thousand Medicare FFS recipients), all in log terms. The blue solid lines show point estimates for the effect of the CBP for duals / No SA / No OSA diagnosis and the red dashed lines show point estimates for the effect of the CBP for nonduals / SA / OSA diagnosed. Vertical lines show the 95 percent confidence interval for those coefficients, based upon standard errors that are clustered at the CBSA level. All regressions include CBSA fixed effects, year-quarter fixed effects, and their interactions with a dummy variable for each group. All regressions are weighted by Medicare FFS population in 2010. 
Table 6: The Impact of Competitive Bidding on CPAP Quantities by Subgroups

\begin{tabular}{lccccc}
\hline \hline & $\begin{array}{c}(1) \\
\text { Dual vs. } \\
\text { Non-Dual }\end{array}$ & $\begin{array}{c}\text { Female } \\
\text { vs. Male }\end{array}$ & $\begin{array}{c}(3) \\
\text { No SA } \\
\text { vs. SA }\end{array}$ & $\begin{array}{c}\text { (4) } \\
\text { No OSA } \\
\text { vs. OSA }\end{array}$ & $\begin{array}{c}(5) \\
\text { Below vs. Above } \\
\text { Median Propensity }\end{array}$ \\
\hline 1 (Competitive Bidding) * Group 1 & $-0.165^{* * *}$ & $-0.0625^{* * *}$ & $-0.123^{* * *}$ & $-0.132^{* * *}$ & $-0.125^{* *}$ \\
& $(0.0308)$ & $(0.0222)$ & $(0.0350)$ & $(0.0355)$ & $(0.0516)$ \\
1 (Competitive Bidding) * Group 2 & -0.0181 & -0.0293 & -0.0242 & -0.0163 & -0.0197 \\
& $(0.0185)$ & $(0.0210)$ & $(0.0187)$ & $(0.0180)$ & $(0.0205)$ \\
Mean of Dep Var (Group 1) & & & & & \\
Mean of Dep Var (Group 2) & 19.34 & 16.75 & 4.253 & 5.504 & 3.103 \\
$\mathrm{~N}$ & 20.86 & 25.32 & 162.2 & 157.1 & 39.05 \\
\hline \hline
\end{tabular}

Notes: This table presents the results of regression analysis for the effect of the CBP on quantity in different subgroups. The observation is at CBSA by year-quarter by subgroups level. Subgroups are defined as duals vs nonduals, male vs female, whether diagnosed with SA (primary diagnosis recorded as ICD-9 code 327.2 or ICD-10 code G47.3 in an inpatient, outpatient, or physician carrier table) in the previous year, whether diagnosed with OSA (primary diagnosis recorded as ICD-9 code 327.23 or ICD-10 code G47.33) in the previous year, and CPAP propensity above vs below median. OSA/SA diagnosis and CPAP propensity samples are restricted to patients who remained enrolled in Medicare for the current and previous 3 quarters to get full information on their diagnosis (sample period starts from 2009Q4). CPAP propensity is estimated using OSA/SA diagnosis and demographic variables in 2010 (details in Section 4.3). Main variables of interests are the CBP indicator interacting with group dummies (group 1 and 2 corresponding to the order in column title). All regressions include CBSA fixed effects, year-quarter fixed effects, and their interactions with a dummy variable for each group. All regressions are weighted by Medicare FFS population in 2010. Standard errors are clustered at CBSA level. Significance levels: $* 10 \%, * * 5 \%, * * * 1 \%$.

to a reduction in supply. This could occur along two margins: a reduction in the number of firms in the market and/or a reduction in the number of claims per firm. To answer the key policy questions of interest, we use variation driven by dual-eligible status to separate the effects of changes in supply from the effects of changes in demand.

The policy environment suggests a natural difference-in-differences specification: we can compare outcomes for dual eligibles and non-dual eligibles before and after the introduction of the CBP. These two groups face the same suppliers in both periods in each geographic market. Although they may be demographically different, we can test for the existence of differential trends in the period leading up to the introduction of the CBP. Critically, because duals and non-duals face different changes in their out-of-pocket prices, we can separate supply from demand.

The left panel in sub-figure A in Figure 3 depicts the impact on the average price and how this varies over time, while Figure 4 shows the changes in the out-of-pocket cost (OOPC) faced by the two groups. ${ }^{29}$ The total price falls for both groups but the OOPC diverges. OOPC for duals

\footnotetext{
${ }^{29} \mathrm{OOPC}$ is calculated as $20 \%$ of the price for non-dual eligibles and 0 for dual eligibles. This number can be
} 
(solid blue line) remains fixed and very close to zero, while the OOPC for non-duals (dashed red line) falls in line with total prices. Despite this, we again see in the bottom left hand panel that the spending reduction is more pronounced among the duals. As described above, quantities for duals fall, while quantities for non-duals actually rise slightly.

Figure 4: The Impact of Competitive Bidding on CPAP Out-of-Pocket Price

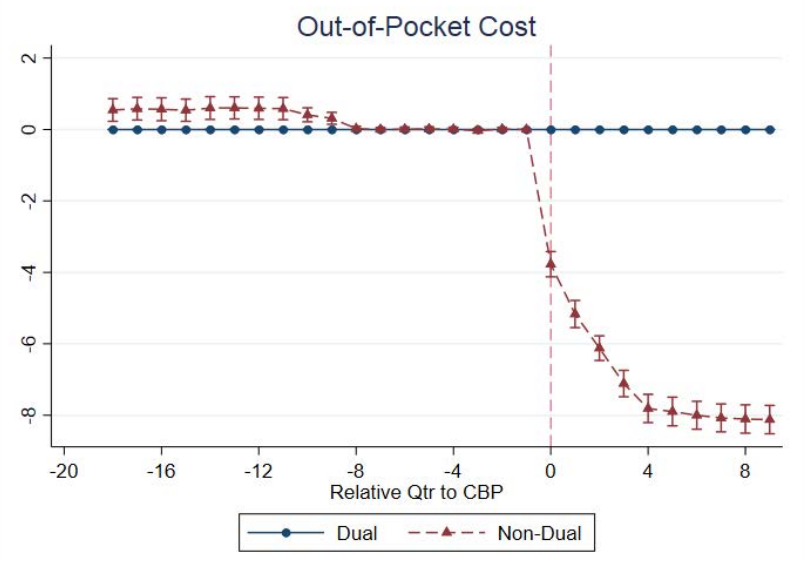

Notes: These figures plot event study coefficients of relative years interacting with dual/nondual dummies. The observation is at geographic area by year-quarter by subgroup level. Outcome variable is out-of-pocket price of CPAP. The blue solid lines show point estimates for the effect of the CBP for duals and the red dashed lines show point estimates for the effect of the CBP for nonduals. Vertical lines show the 95 percent confidence interval for those coefficients, based upon standard errors that are clustered by geographic area. All regressions include geographic area and year-quarter fixed effect, and their interactions with a dummy variable for duals. All regressions are weighted by Medicare FFS population in 2010.

Both the direction and magnitude of these results are consistent with large supply side changes. Absent OOPC changes, quantities supplied fall because of the reduction in price. A differential demand response among non-duals mitigates this quantity reduction since consumers actually face a lower price after the CBP. Given elasticity estimates, we can predict counterfactual quantities under alternative policies. To measure the demand elasticity, we leverage the differences in cost sharing rules across "dual" and "non-dual" beneficiaries directly. Formally, let $G$ be a dummy variable that takes on a value of 1 for non-duals. We can calculate the total quantity $D$ in market $m$ at time $t$ for group $g$ in $G$ or $1-G: D_{g m t}$. We know that for non-duals $(G=1), O O P C_{g m t}=$ $0.2 * P_{g m t}$; for duals, $O O P C_{g m t}=0$. The elasticity (which we can evaluate at the average $O O P C$ )

different from the actual out-of-pocket payment if the beneficiary has Medigap coverage, which will bias us against finding any difference across the two groups. We explore this issue below. 
can be written as:

$$
\varepsilon=\frac{\partial D}{\partial O O P C} \frac{O O P C}{D}=\frac{\partial \log (D)}{\partial O O P C} O O P C
$$

Intuitively, we are using exactly the variation depicted in Figure 4, comparing duals and nonduals before and after competitive bidding. The previous figures effectively plot the first-stage and reduced form using this variation, which we describe in Table 7.

Table 7: The Impact of Competitive Bidding on CPAP Demand

\begin{tabular}{lcccc}
\hline \hline & $(1)$ & $(2)$ & $(3)$ & $(4)$ \\
& OOPC & $\begin{array}{c}\text { Log } \\
\text { Quantity }\end{array}$ & $\begin{array}{c}\text { Log } \\
\text { Beneficiaries }\end{array}$ & $\begin{array}{c}\text { Log New } \\
\text { Beneficiaries }\end{array}$ \\
\hline Panel A: OLS & & & & \\
1 (Competitive Bidding)*Nondual & $-7.183^{* * *}$ & $0.124 * * *$ & $0.115^{* * *}$ & $0.110^{* * *}$ \\
& $(0.174)$ & $(0.0219)$ & $(0.0207)$ & $(0.0229)$ \\
$1($ Competitive Bidding) & 0 & $-0.149^{* * *}$ & $-0.139^{* * *}$ & $-0.139^{* * *}$ \\
& & $(0.0258)$ & $(0.0240)$ & $(0.0221)$ \\
\hline Panel B: IV & & & & \\
OOPC & & $-0.0173 * * *$ & $-0.0160^{* * * *}$ & $-0.0153 * * *$ \\
& & $(0.00310)$ & $(0.00292)$ & $(0.00309)$ \\
$1($ Competitive Bidding) & & $-0.149 * * *$ & $-0.139 * * *$ & $-0.139 * * *$ \\
& & $(0.0258)$ & $(0.0240)$ & $(0.0221)$ \\
Elasticity & & & & \\
Mean of OOPC (Nondual) & 15.76 & -0.272 & -0.251 & -0.242 \\
$\mathrm{~N}$ & 50,477 & 50,477 & 50,477 & 41,656 \\
\hline \hline
\end{tabular}

Notes: This table presents the results of regression analysis for the effect of the CBP on price and quantity of CPAP separately among duals and non-duals. The observation is at CBSA by year-quarter by dual/nondual level. Outcome variables include out-of-pocket cost (OOPC, defined as $20 \%$ of price for non-dual and 0 for dual), quantity and number of (new) beneficiaries, all denominated by one thousand Medicare FFS beneficiaries, and all in log terms except OOPC. Panel A shows the OLS result, while Panel B shows the IV result using 1(Competitive Bidding)*Nondual as the instrument for OOPC. All regressions include CBSA fixed effects, year-quarter fixed effects, and their interactions with a dummy variable for dual eligible status. All regressions are weighted by Medicare FFS population in 2010. Standard errors are clustered at CBSA level. Significance levels: *10\%, $* * 5 \%, * * * 1 \%$.

The first column in Panel A describes the relationship between competitive bidding and OOPC.

Columns 2-4 in Panel B estimate the corresponding 2SLS regressions in which we include group fixed effects, time fixed effects, market fixed effects, and a "post" dummy in both stages of the regression. The excluded instrument is a "post" dummy interacted with $G$. We scale the coefficient to obtain a demand elasticity. The coefficient in column 2 Panel B (-0.0173) corresponds to the coefficient in column 2 Panel A (0.124) divided by the coefficient in column $1(-7.183)$. The 
estimate suggests that a one dollar reduction in out-of-pocket cost, which represents a 6.34 percent reduction at the mean of 15.76 (among non-duals in 2010), leads to an increase of 1.73 percent in the quantity demanded. Taking the ratio of these two changes, we estimate a demand elasticity of -0.272. The estimate is very similar across specifications (using different dependent variables) and is close to the elasticity estimate of 0.2 for overall health care utilization in the well-known RAND health insurance experiment (Manning et al., 1987).

Our results indicate that demand is indeed downward sloping. Despite this, quantities fall postcompetitive bidding, consistent with a large supply-side response to the policy-induced reduction in price. A natural question is how much demand would have increased absent these supply side changes. If we applied the same demand elasticity to non-duals, we would expect only a $2.8 \%$ decrease in quantity $(0.149-(-0.272) *(0.2 *(-35) / 15.76))$. This indicates that a demand response insulated non-duals from much of the negative quantity impact of the policy change, which is consistent with the event study plots in Figure 3 and OLS results for subgroups in Table 6.

Our demand elasticity estimation leverages different OOPC changes among duals and nonduals assuming that non-duals pay $20 \%$ coinsurance and therefore faced a OOPC reduction after the CBP. This might be attenuated if non-duals have supplemental insurance insulating them from cost-sharing. In fact, Medicare Supplement (Medigap) insurance would cover the 20\% Part B copay associated with CPAP machines. We do not observe supplemental coverage at the individual level. However, we know how prevalent coverage is at the market level. To explore the impact of supplemental coverage on our elasticity estimates, we split the sample into above and below median Medigap coverage markets (average Medigap share is $37.6 \%$ and $25.5 \%$ respectively). Theoretically, one would expect a smaller quantity differential between duals and non-duals in high-Medigap states given that non-duals are more likely to be insulated from the effects of any price changes in high-Medigap states. Consistent with this, the results displayed in Table 8 show that quantity effect for non-duals is smaller in the below-median markets; the negative impact for duals is almost completely offset. The interaction term is smaller in markets where Medigap coverage is more prevalent; the quantity reduction for duals is more like non-duals. The "naive" 
Table 8: The Impact of Competitive Bidding on CPAP Demand By Medigap Share

\begin{tabular}{|c|c|c|c|c|c|}
\hline & $\begin{array}{c}(1) \\
\text { Below } \\
\text { Median }\end{array}$ & $\begin{array}{c}\text { (2) } \\
\text { Above } \\
\text { Median }\end{array}$ & $\begin{array}{c}(3) \\
\text { Bottom } \\
\text { Tercile }\end{array}$ & $\begin{array}{c}(4) \\
\text { Middle } \\
\text { Tercile }\end{array}$ & $\begin{array}{c}(5) \\
\text { Top } \\
\text { Tercile }\end{array}$ \\
\hline & \multicolumn{5}{|c|}{ Log Quantity } \\
\hline \multicolumn{6}{|l|}{ Panel A: OLS } \\
\hline 1(Competitive Bidding)*Nondual & $\begin{array}{c}0.157 * * * \\
(0.0335)\end{array}$ & $\begin{array}{c}0.0952 * * * \\
(0.0266)\end{array}$ & $\begin{array}{c}0.189 * * * \\
(0.0389)\end{array}$ & $\begin{array}{c}0.0874 * * * \\
(0.0318)\end{array}$ & $\begin{array}{c}0.0935 * * * \\
(0.0354)\end{array}$ \\
\hline 1(Competitive Bidding) & $\begin{array}{c}-0.189 * * * \\
(0.0414)\end{array}$ & $\begin{array}{c}-0.107 * * * \\
(0.0273)\end{array}$ & $\begin{array}{c}-0.228 * * * \\
(0.0480)\end{array}$ & $\begin{array}{c}-0.104 * * * \\
(0.0327)\end{array}$ & $\begin{array}{c}-0.0879 * * * \\
(0.0326) \\
\end{array}$ \\
\hline \multicolumn{6}{|l|}{ Panel B: IV } \\
\hline OOPC & $\begin{array}{c}-0.0215 * * * \\
(0.00485)\end{array}$ & $\begin{array}{c}-0.0134 * * * \\
(0.00372)\end{array}$ & $\begin{array}{c}-0.0262 * * * \\
(0.00581)\end{array}$ & $\begin{array}{c}-0.0129 * * * \\
(0.00462)\end{array}$ & $\begin{array}{r}-0.0120 * * \\
(0.00467)\end{array}$ \\
\hline 1(Competitive Bidding) & $\begin{array}{c}-0.189 * * * \\
(0.0414)\end{array}$ & $\begin{array}{c}-0.107 * * * \\
(0.0273)\end{array}$ & $\begin{array}{c}-0.228 * * * \\
(0.0480)\end{array}$ & $\begin{array}{c}-0.104 * * * \\
(0.0327)\end{array}$ & $\begin{array}{c}-0.0879 * * * \\
(0.0326)\end{array}$ \\
\hline Elasiticity & -0.341 & -0.211 & -0.414 & -0.199 & -0.194 \\
\hline Mean of OOPC (Nondual) & 15.81 & 15.69 & 15.85 & 15.44 & 16.08 \\
\hline Medigap Share & 25.54 & 37.58 & 23.19 & 32.67 & 41.29 \\
\hline $\mathrm{N}$ & 24,988 & 25,250 & 17,154 & 16,278 & 16,806 \\
\hline
\end{tabular}

Notes: This table replicates Table 7 column 2 presenting demand elasticity estimation within subgroups of CBSAs based on share of traditional Medicare beneficiaries with Medigap coverage. The observation is at CBSA by year-quarter by dual/nondual level. Outcome variable is log quantity (denominated by one thousand Medicare FFS beneficiaries). Panel A shows the OLS result, while Panel B shows the IV result using 1(Competitive Bidding)*Nondual as the instrument for OOPC. Medigap share in each CBSA is calculated using state level Medigap share reported in AHIP (2017) based on 2015 National Association of Insurance Commissioners (NAIC) data. For CBSAs across state borders, average Medigap share is calculated using 2015 FFS Medicare population as weight. Columns 1-2 cut the sample into CBSAs above or below median Medigap share, and columns 3-5 cut the sample into tercile. All regressions include CBSAs fixed effects, year-quarter fixed effects, and their interactions with dummy variable for dual eligible status. All regressions are weighted by Medicare FFS population in 2010. Standard errors are clustered at CBSA level. Significance levels: $* 10 \%, * * 5 \%, * * * 1 \%$.

elasticity estimates are also larger in magnitude: -0.341 in below-median markets versus -0.211 in above-median markets. While the range of elasticity estimates is non-trivial, the elasticity estimate is below -0.5 in all subsamples. ${ }^{30}$ Additional sub-samples by terciles or isolating the top quartile show a consistent pattern: the "naive" elasticity estimate ranges from approximate -0.19 in markets where Medigap is especially prevalent to -0.41 in markets where Medigap coverage is rare. Our approach allows us to isolate the impact of consumer behavior and provide policy-relevant elasticities that account for market institutions.

There are two potential concerns when comparing dual eligible patients with non-duals, both related to Medicaid payment policy. First, Medicaid reimbursement could change at the same time that the CBP takes effect. We test this assumption using robustness checks with a state-by-

\footnotetext{
${ }^{30}$ We also estimate demand elasticity in different subgroups of Medigap share areas using the pooled sample of 12 lead items and see a similar pattern: -0.108 in below-median markets versus -0.0444 in above-median markets.
} 
post-CBP indicator, which turns on when any place in the state has been included in the CBP. For both main effects (Table 4) and dual analysis (Table 7), we find similar results as in Table A4 and Table A5 after controlling for changes in state-level policies that coincide with the CBP. Second, if Medicaid does not pay the full out-of-pocket cost after Medicare pays for the crossover claims, lowering the price in Medicare would cause different changes in the payment that suppliers receive for dual and non-dual patients. ${ }^{31}$ As a robustness check, we restrict the sample for dual analysis to be states that 1) set Medicaid price the same as Medicare price for DME items (AL, AK, DE, IN, IA, MN, MT, NV, NM, NC, WV, WY), or 2) have full crossover payment for Part B services (AR, HI, IA, ME, MS, MO, NE, OH, OK, SD, VT, WY). ${ }^{32}$ Results are presented in Appendix Table A6 and yield a similar estimate for the demand elasticity. Finally, we also replicate the dual analysis using the pooled sample of 12 lead items in Appendix Table A7. The elasticities are similar to the CPAP estimates for new consumers but smaller for existing consumers. This is consistent with more within-category substitution in other DME product categories.

The quantity reduction among duals suggests a supply-side response to reduced reimbursement, consistent with provider responses in other healthcare markets (Clemens and Gottlieb, 2014). To use the data to construct a supply elasticity or measure firm costs, we would also need an assumption on firm conduct. This is an important direction for future work. From a normative perspective, it is not clear whether the reduction in quantity along with the fall in Medicare spending is "good" or "bad," because we have not specified the socially optimal level of CPAP consumption. Furthermore, it is difficult to determine whether the CBP led to a reduction in consumption among consumers for whom CPAP machines are clinically appropriate.

\footnotetext{
${ }^{31} \mathrm{~A}$ crossover claim is a claim for a recipient who is eligible for both Medicare and Medicaid, where Medicare pays a portion of the claim and Medicaid is billed for any remaining deductible and/or coinsurance.

${ }^{32}$ Information from MACPAC States' Medicaid Fee-for-Service Durable Medical Equipment Payment Policies, https://www.macpac.gov/publication/ states-medicaid-fee-for-service-durable-medical-equipment-payment-policies/. Information from MACPAC State Medicaid Payment Policies for Medicare Cost Sharing, https://www.macpac.gov/ wp-content/uploads/2015/01/State-Medicare-Cost-Sharing-2015.xlsx Note that there is no specific summary for payment policy on DME items, therefore we refer to policy on physician services which is also paid under Medicare Part B
} 


\subsection{Clinical Appropriateness}

To investigate the welfare effects of the changes described above, we note that we observe very different utilization patterns for consumers with and without a sleep apnea diagnosis. We will use this heterogeneity to explore the allocative efficiency of the CBP. Following Chandra and Staiger (2007), we define the clinical appropriateness for treatment using pre-period data on diagnoses and demographics. We then explore the extent to which the CBP reduced "appropriate" CPAP use given the clinical literature.

To develop intuition, we first describe the pathways that lead to CPAP claims. Conditional on symptoms, a patient may decide to visit his or her doctor. The doctor may diagnose the patient as having one or more forms of sleep apnea. ${ }^{33}$ Conditional on a sleep apnea diagnosis, the patient may be prescribed a CPAP machine.

Given that only CPAP prices (and not for example physician reimbursement) are affected by the CBP, we do not expect a change in upstream diagnoses unless consumer and/or physician behavior changes. Previous results summarized above in Table 5 demonstrated that overall diagnosis rates did not change as a result of the CBP and Appendix Figure A2 further shows that the number of diagnoses is not affected by the timing of the CBP. Furthermore, there is no difference in trends between duals and nonduals in terms of the diagnosis rate of sleep apnea. The left-hand panel of Appendix Figure A3 shows the impact of the CBP on the probability of having any sleep apnea (SA) diagnosis in the past year (current quarter + previous 3 quarters, and the right-hand panel shows the probability of having OSA diagnosis in the past year (current quarter + previous 3 quarters). In both cases, the diagnosis rate increased by around 0.001 percentage points among each group (with non-duals slightly higher), which is relatively small compared to the mean of $2.9 \%$ for OSA and $3.3 \%$ for SA.

To model the utilization of CPAP devices conditional on demographic and clinical data, let $\zeta$ be a vector of consumer characteristics, including clinical appropriateness for CPAP treatment, $Z$. We define the population by a joint distribution $G(\zeta)$. We write a consumer $i$ of type $\zeta$ 's

\footnotetext{
${ }^{33}$ For example, in obstructive sleep apnea, the upper airways become blocked during sleep.
} 
utility from CPAP consumption as $v\left(\zeta_{i}, O O P C\right)$, where $O O P C$ is the price faced by the consumer. We can then define the price at which a consumer is indifferent to owning a CPAP machine as $\sigma\left(\zeta_{i}\right)=\max \left(O O P C: v\left(\zeta_{i}, O O P C\right)>0\right)$. We note that, given the inconvenience and treatment costs, this quantity could be negative. We can then write aggregate demand as:

$$
D(O O P C)=\int 1\left(\sigma\left(\zeta_{i}\right) \geq O O P C\right) d G(\zeta)=\operatorname{Pr}\left(\sigma\left(\zeta_{i}\right) \geq O O P C\right)
$$

Now let the clinical appropriateness for treatment $Z_{i}$ be one component of the vector $\zeta$. The average clinical appropriateness in a market can be written as:

$$
\bar{Z}(O O P C)=\frac{1}{D(O O P C)} \int Z_{i} 1\left(\sigma\left(\zeta_{i}\right) \geq O O P C\right) d G(\zeta)=E\left(Z_{i} \mid \sigma\left(\zeta_{i}\right) \geq O O P C\right)
$$

We are interested in $\frac{\partial \bar{Z}(O O P C)}{\partial O O P C}$, which also allows us to define the clinical appropriateness of the marginal consumer. We can estimate $\frac{\partial \bar{Z}(O O P C)}{\partial O O P C}$ using an exogenous change in $O O P C$.

To construct a measure of clinical appropriateness for treatment $Z_{i}$, we take a series of steps. First, we predict CPAP consumption in the pre-period. To do this, we estimate a logit regression using beneficiary-year data. ${ }^{34}$ To avoid potential changes after the CBP, only the pre-CBP year of 2010 is used for estimation. We then predict the CPAP usage probability for all beneficiary-years and aggregate to the geographic area by year level. We use a number of clinical and demographic predictors of CPAP usage: OSA diagnosis, SA diagnoses, age bins, gender, dual and SSDI (social security disability insurance) status.

The results from this analysis are summarized in Table 9. As the results there show, diagnosis is a very strong predictor of CPAP use. A beneficiary with a SA diagnosis is $76.7\left(e^{4.353}-1\right)$ times higher in odds ratio of having a CPAP claim than a beneficiary without such a diagnosis. The oldest beneficiaries are significantly less likely to have one or more CPAP claims, as are duals and women. Using these results, we can construct the empirical analogue of $Z_{i}$ above - the

\footnotetext{
${ }^{34} \mathrm{We}$ restrict attention to beneficiaries with full 3-month Part B non-HMO Medicare enrollment in the current quarter and three previous quarters.
} 
Table 9: Predict CPAP

\begin{tabular}{lcc}
\hline \hline & \multicolumn{2}{c}{ CPAP } \\
\cline { 2 - 3 } & Beta & SE \\
OSA & $0.803^{* * *}$ & $(0.00939)$ \\
SA & $4.353^{* * *}$ & $(0.0101)$ \\
Male & $0.147 * * *$ & $(0.00532)$ \\
Age group (65-69 as baseline) & & \\
$<65$ & $-0.0512^{* * *}$ & $(0.0179)$ \\
$70-74$ & $-0.189^{* * *}$ & $(0.00770)$ \\
$75-79$ & $-0.325^{* * *}$ & $(0.00864)$ \\
$80-84$ & $-0.528^{* * *}$ & $(0.0104)$ \\
$85-89$ & $-0.891^{* * *}$ & $(0.0156)$ \\
$90+$ & $-1.656^{* * *}$ & $(0.0341)$ \\
Dual & $-0.163^{* * *}$ & $(0.00742)$ \\
SSDI & $-0.151^{* * *}$ & $(0.0177)$ \\
& & \\
Observations & $23,927,627$ \\
R2_p & \multicolumn{2}{c}{0.413} \\
\hline \hline
\end{tabular}

Notes: This table presents the results of predicting CPAP utilization using beneficiaries' demographic characteristics and diagnosis. The observation is at beneficiary level, restricting to beneficiaries with continuous Part B non-HMO Medicare enrollment in the current quarter and three previous quarters. To avoid potential changes after the CBP, only the pre-CBP year 2010 is used for estimation. OSA diagnosis is identified as primary diagnosis ICD-9 code 327.23 or ICD-10 code G47.33 in an inpatient, outpatient or physician carrier table. SA diagnosis is identified as all codes under ICD-9 code 327.2 or ICD-10 code G47.3. Significance levels: $* 10 \%, * * 5 \%, * * * 1 \%$.

clinical appropriateness of treatment. We note that this variable measures clinical appropriateness conditional on the administrative price mechanism.

We next plot the impact of competitive bidding for consumers with above and below median CPAP propensities. The results are in Figure 5. As noted above, prices fall similarly for those with above and below median clinical appropriateness. ${ }^{35}$ However, the quantity series diverge. For consumers with above median clinical appropriateness for treatment, quantities are virtually unchanged. However, there is a large and persistent drop in CPAP use for consumers with below median predicted CPAP propensity. Taken together, these results suggest that utilization declined

\footnotetext{
${ }^{35}$ The small differences are again due to the use of grandfathered suppliers.
} 
more for those who derive less benefit from CPAP use.

Figure 5: The Impact of Competitive Bidding on CPAP Prices and Quantities by CPAP Propensity
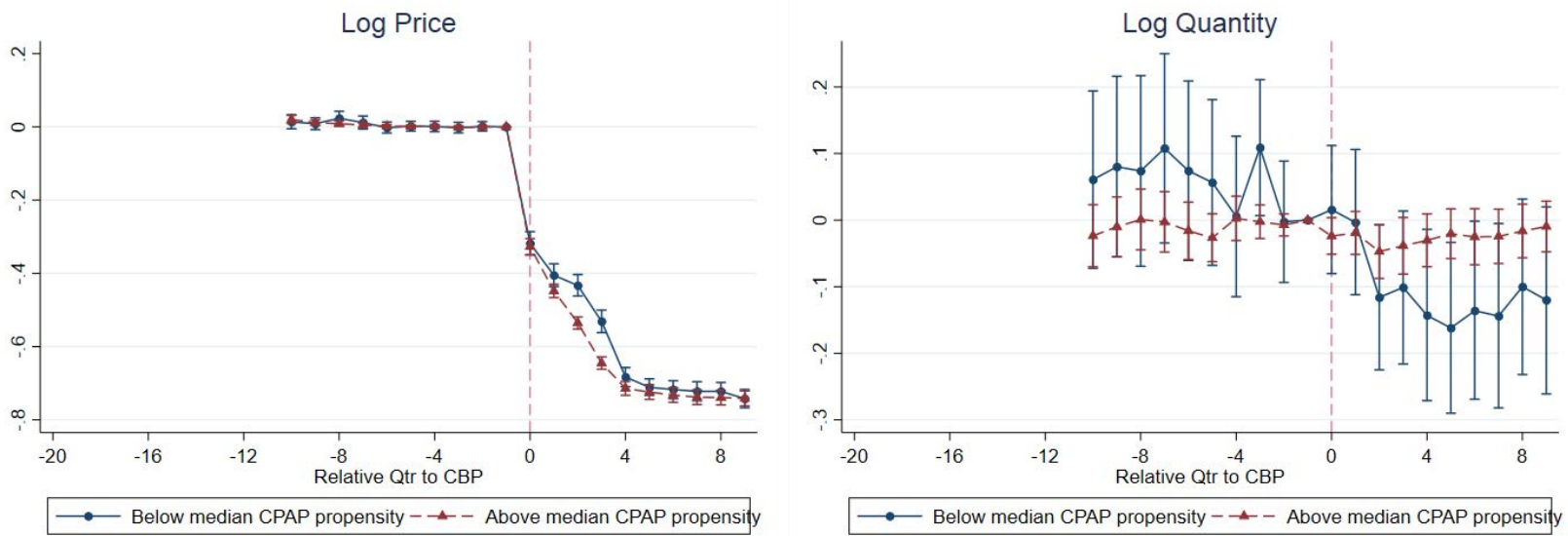

Notes: These figures plot event study coefficients of relative years interacting with group dummies (estimated CPAP propensity below vs. above median). CPAP propensity is estimated using OSA/SA diagnosis and demographic variables in 2010, restricted to patients who remained enrolled in Medicare for the current and previous 3 quarters to get full information on their diagnosis. The observation is at CBSA by year-quarter by subgroup level. Outcome variables include price and quantity (total number of product/service counts per 1000 Medicare FFS recipients), all in log terms. The blue solid lines show point estimates for the effect of the CBP for CPAP propensity below median and the red dashed lines show point estimates for the effect of the CBP for CPAP propensity above median. Vertical lines show the 95 percent confidence interval for those coefficients, based upon standard errors that are clustered at the CBSA level. All regressions include CBSA fixed effects, year-quarter fixed effects, and their interactions with a dummy variable for each group. All regressions are weighted by Medicare FFS population in 2010.

Our results suggest that some of the quantity reduction that we observe may be "efficient"; that is, the quantity reductions are concentrated among consumers for whom a CPAP machine is less likely to be clinically appropriate. To further explore this idea, we isolate the "marginal" consumers in an additional set of specifications. To do this, we follow the logic of Gruber et al. (1999). We estimate the following equation:

$$
Y_{s t}=\beta_{1} \cdot \log \left(D_{s t} / M_{s t}\right)+\sigma_{s}+\theta_{t}+\varepsilon_{p s t},
$$

where $Y_{s t}$ is the average demographic characteristics of CPAP users (corresponding to variables we used to define subgroups in Table 6) and the endogenous independent variable of interest is the $\log$ of the CPAP rate, calculated as total demand $D_{s t}$ divided by Medicare beneficiaries $M_{s t}$. The excluded instrument is the interaction from the difference in difference specification described 
above. The coefficients estimate the gap in demographics and outcomes between the marginal and the average consumer, where the marginal consumer is less likely to obtain a CPAP post-CBP.

Table 10: Marginal Consumer of CPAP

\begin{tabular}{lccccc}
\hline \hline & $(1)$ & $(2)$ & $(3)$ & $(4)$ & $(5)$ \\
& Dual & Male & $\begin{array}{c}\text { SA } \\
\text { Diagnosed }\end{array}$ & $\begin{array}{c}\text { OSA } \\
\text { Diagnosed }\end{array}$ & $\begin{array}{c}\text { CPAP } \\
\text { Propensity }\end{array}$ \\
\hline Log CPAP rate & $0.460^{* * * *}$ & $-0.160^{*}$ & $-0.498^{* * *}$ & $-0.680^{* * *}$ & $-0.0956^{* *}$ \\
& $(0.155)$ & $(0.0908)$ & $(0.166)$ & $(0.215)$ & $(0.0456)$ \\
& & & & & \\
Mean & 0.186 & 0.546 & 0.781 & 0.712 & 0.201 \\
N & 26,762 & 26,762 & 26,726 & 26,726 & 19,108 \\
Year-Quarter FE & Yes & Yes & Yes & Yes & Yes \\
CBSA FE & Yes & Yes & Yes & Yes & Yes \\
\hline \hline
\end{tabular}

Notes: This table presents the results of regression analysis for the effect of the CBP on price and quantity of CPAP. The observation is at CBSA by year-quarter level. For SA and OSA diagnosis, we restrict to patients who remained enrolled in Medicare for the current and previous 3 quarters to get full information on their diagnosis (sample period starts 2009Q4). For CPAP propensity which is estimated using 2010 data, we only use observations since 2011Q1 to estimate marginal consumer. Outcome variables include average CPAP propensity predicted as shown above, demographic characteristics and SA/OSA diagnosed. We instrument for the explanatory variable, Log CPAP rate, using the treatment indicator of the CBP. All regressions include CBSA fixed effects and year-quarter fixed effects. All regressions are weighted by Medicare FFS population in 2010. Standard errors are clustered at CBSA level. Significance levels: *10\%, **5\%, ***1\%.

Column 5 of Table 10 shows that marginal consumers are $0.0956 \mathrm{pp}$ lower in CPAP propensity than average consumers, as suggested by the graphical analyses. Columns 1-2 show that marginal consumers are more likely to be duals, consistent with our findings that duals reduce quantity more, and are less likely to be male. Columns 3 and 4 show that marginal consumers are also less likely to have an SA or OSA diagnosis in the past year, again consistent with our findings with subgroups.

\section{Policy Analysis}

To draw normative conclusions about the impact of the CBP, we must view our results in context. A full accounting of the welfare impacts of this significant change to the Medicare reimbursement policy is outside the scope of this paper. However, we develop a simple cost-benefit comparison from the government's perspective that also incorporates the effects on patient health. We begin 
with the approximation that the benefits of competitive bidding are the savings on inframarginal units: $d P * D_{2}$. The costs of competitive bidding may fall on the government or on consumers. First, government expenditures may increase (decrease) if other covered services are substitutes (complements) for competitive bidding items; let $E$ represent such average government expenditure. Second, consumers value consumption of durable medical goods; let $B$ represent (monetized) health benefits to consumers and let $\eta$ represent the weight that the government places on consumer benefits.

The benefits of competitive bidding exceed the costs if and only if:

$$
d P * D_{2}>d E+\eta d B
$$

The first three objects in this equation are easy to calculate. According to Table 4, the average price drop is $e^{-0.594}-1=44.8 \%$ from a baseline average price of $\$ 71.33$, which gives us $d P=$ $44.8 \% * \$ 71.33=\$ 31.96$ per month, or $\$ 415.43$ over the thirteen month rental period. We can multiply this by the number of inframarginal units; 8.30 beneficiaries per one thousand Medicare beneficiaries have a CPAP claim. Therefore, the total savings are $\$ 3448.07$ per one thousand Medicare beneficiaries. In Table 5, we show that (non-DME) Medicare expenditures actually fall post-competitive bidding; we (conservatively) ignore $d E$.

The last object - the loss of the health benefits to consumers no longer purchasing DME under competitive bidding - is harder to calculate. While we can characterize marginal consumers, our empirical analysis makes it difficult to measure their willingness-to-pay. ${ }^{36}$ To quantify the benefits of a CPAP machine, we turn to the clinical literature. We measure the health benefits of CPAP machines in terms of quality-adjusted life years (QALYs); 1 QALY is one year in perfect health. We then calculate the "cost-per-QALY", known as an incremental cost-effectiveness ratio (ICER). According to external estimates from the United Kingdom's National Institute for Health and Care

\footnotetext{
${ }^{36}$ We know that (for non-dual) consumers, willingness to pay is at least $.2 * P_{1}$. However, we are probably more interested in the upper bound; this requires considering the "worst case scenario" from the perspective of the consumer. There are two main concerns. The first, and potentially more damaging, is that changes in reimbursement could lead to under-diagnosis. Second, changes in reimbursement could lead to increases in spending elsewhere in the medical system. Medicare will still cover all of the services associated with a sleep apnea diagnosis.
} 
Excellence (NICE, 2008), the cost for the average consumer is $£ 20,585$ per QALY for patients with mild OSA, assuming a CPAP price of $£ 250-£ 550$. Given the midpoint of that estimate, we calculate that a CPAP generates 0.0194 QALYs (400 / 20585). For moderate and severe OSA, NICE estimated $£ 9391$ and $£ 4413$ per QALY respectively, which leads to CPAP values of 0.042 and 0.091 per QALY.

We can calculate the change in the number of consumers from our estimates: there are 0.37 $\left.\left(e^{-0.0439}-1\right) * 8.30\right)$ fewer CPAP consumers per one thousand Medicare beneficiaries. The benefits of the CBP will exceed its costs if the value of a QALY is less than the savings divided by the number of new consumers multiplied by the benefits (in QALYs) per consumer. In our setting, this is given by $3448.07 /(0.0194 * 0.37)=\$ 480,366.40$. The QALY threshold is $\$ 221,883.53$ if the marginal CPAP user has moderate OSA, or $\$ 102,407.78$ if the marginal CPAP user has severe OSA. In our analyses above we find that the marginal consumer has a lower CPAP propensity than the average consumer, so they are less likely to have severe OSA. Estimates within the literature value a year of life in perfect health at $\$ 75,000$ to $\$ 100,000$ (Cutler and Meara, 2000). Therefore, we find that the saving from the reduction in Medicare spending substantially exceed the welfare costs of reduced access to CPAP devices in our setting.

Taken together, our results suggest that the benefits of the lower health care expenditures outweigh any welfare loss from reduced quantity. However, there are several caveats. We do not account for supplier profits, nor is this meant to be a complete welfare analysis. We make several assumptions - about both social welfare weights and cash prices - that are not innocuous. However, our conservative estimates still highlight the potential for large government savings under the program. Future work should explore optimal reimbursement policy.

\section{Conclusion}

We estimate the impact of Medicare's CBP, which was introduced a decade ago. We find that the roll-out of competitive bidding -- staggered across product, space, and time -- led to large reduc- 
tions in the prices paid for DME. Reductions in quantities accompanied these price reductions. We explore the CPAP market in particular to show that the marginal consumer is more likely to be a dual-eligible who faces no cost-sharing. The results suggest that changes in supply, rather than demand, are driving the overall reduction in quantity.

To separate supply and demand-side factors, we compare the impact of the CBP on dual eligible and non-dual eligible Medicare enrollees. We show that reductions in out-of-pocket costs mitigate the impact of the program on utilization; there are no reductions in quantities for non-dual eligibles (who see a reduction in their out-of-pocket price as a result of the CBP). Finally, we show that rates of diagnosis do not change. The reduction in quantity is significantly higher among consumers without a formal sleep apnea diagnosis. Our model and empirical analysis indicates these consumers are less clinically appropriate for treatment. Given our results for price, utilization, and Medicare spending, we perform a cost benefit analysis. The calculations indicate that the benefits of the price reduction on infra-marginal units more than offsets the costs of any loss in consumer surplus.

While highlighting the success of the CBP in reducing Medicare spending, our findings suggest that Medicare faces a serious challenge in setting prices for health care services within its fee-forservice program. While most Medicare recipients obtain coverage for prescription drugs through private Medicare Part D plans and nearly 40 percent obtain their health insurance through private Medicare Advantage plans, the majority of Medicare recipients have traditional Medicare fee-forservice coverage. Future work should consider whether market mechanisms such as competitive bidding could be effective in other areas of Medicare's fee-for-service program.

In both regulation and procurement, governments often face serious challenges. Governments may lack the information necessary to set prices at the efficient level (Chan and Dickstein, 2019). The problems they face are often challenging and complex, especially in health care. As the same time, there are looming challenges for Medicare financing, with expenditures for the program projected to more than double from 750 billion in 2018 to 1.559 trillion by 2028 . This would represent a 7.6 percent annual growth rate in total spending (5.0 percent annual on a per-recipient 
basis) compared with an annual growth rate in total spending of just 4.9 percent during the preceding 10 years (CMS, 2020b). Our results suggest that Medicare's future funding challenges could be reduced by targeted reforms of price-setting in this program, which currently provides health insurance to one-in-five Americans. 


\section{References}

AHIP. Trends in medigap enrollment and coverage options, 2015, 2017. https://www . ahip. org/wp-content/uploads/2017/05/Medigap_Report_5.1.17.pdf.

G. F. Anderson, U. E. Reinhardt, P. S. Hussey, and V. Petrosyan. It's the prices, stupid: why the united states is so different from other countries. Health Affairs, 22(3):89-105, 2003.

D. C. Chan and M. J. Dickstein. Industry input in policy making: Evidence from medicare. The Quarterly Journal of Economics, 134(3):1299-1342, 2019.

A. Chandra and D. O. Staiger. Productivity spillovers in health care: evidence from the treatment of heart attacks. Journal of Political Economy, 115(1):103-140, 2007.

A. Chandra, A. Finkelstein, A. Sacarny, and C. Syverson. Health care exceptionalism? performance and allocation in the us health care sector. American Economic Review, 106(8):2110-44, 2016.

S. J. Choi, E. Y. Joo, Y. J. Lee, and S. B. Hong. Suicidal ideation and insomnia symptoms in subjects with obstructive sleep apnea syndrome. Sleep medicine, 16(9):1146-1150, 2015.

J. Clemens and J. D. Gottlieb. Do physicians' financial incentives affect medical treatment and patient health? American Economic Review, 104(4):1320-49, 2014.

J. Clemens and J. D. Gottlieb. In the shadow of a giant: Medicareâs influence on private physician payments. Journal of Political Economy, 125(1):1-39, 2017.

J. Clemens, J. D. Gottlieb, and T. L. Molnár. Do health insurers innovate? evidence from the anatomy of physician payments. Journal of health economics, 55:153-167, 2017.

CMS. Medicare part a and part b summary: Persons with utilization, program payments, and cost sharing for all original medicare beneficiaries, by type of coverage and type of service, calendar years 2010-2015, 2015. https://www.cms.gov/ 
Research-Statistics-Data-and-Systems/Statistics-Trends-and-Reports/ CMSProgramStatistics/2015/Downloads/UTIL/2015_CPS_MDCR_SUMMARY_AB_1.pdf.

CMS. Cms fast fact: Medicare, medicaid, and chip populations for cy 2020, 2020a. https://www.cms.gov/Research-Statistics-Data-and-Systems/ Statistics-Trends-and-Reports/CMS-Fast-Facts.

CMS. National health expenditure projections 2019-2028, 2020b. https://www.cms . gov/Research-Statistics-Data-and-Systems/Statistics-Trends-and-Reports/ NationalHealthExpendData/NationalHealthAccountsProjected.

Z. Cooper, S. V. Craig, M. Gaynor, and J. Van Reenen. The price ainât right? hospital prices and health spending on the privately insured. The Quarterly Journal of Economics, 134(1):51-107, 2019.

P. Cramton, S. Ellermeyer, and B. Katzman. Designed to fail: The medicare auction for durable medical equipment. Economic Inquiry, 53(1):469-485, 2015.

V. Curto, L. Einav, A. Finkelstein, J. Levin, and J. Bhattacharya. Health care spending and utilization in public and private medicare. American Economic Journal: Applied Economics, 11(2): $302-32,2019$.

D. M. Cutler and E. Meara. The technology of birth: Is it worth it? In Forum for Health Economics \& Policy, volume 3. De Gruyter, 2000.

D. Dranove, C. Ody, and A. Starc. A dose of managed care: Controlling drug spending in medicaid. American Economic Journal: Applied Economics, forthcoming.

M. Duggan and V. Scimeca. State of the Union: Health. Stanford Center on Poverty and Inequality, 2018.

M. Duggan and F. Scott Morton. The effect of medicare part d on pharmaceutical prices and utilization. American Economic Review, 100(1):590-607, 2010. 
M. Duggan and F. M. Scott Morton. The distortionary effects of government procurement: evidence from medicaid prescription drug purchasing. The Quarterly Journal of Economics, 121 (1):1-30, 2006.

GAO. Review of the first year of cmsâs durable medical equipment competitive bidding programâs round 1 rebid, 2012.

GAO. Cms's round 2 durable medical equipment and national mail-order diabetes testing supplies competitive bidding programs, 2016.

J. Gruber, P. Levine, and D. Staiger. Abortion legalization and child living circumstances: who is the âmarginal childâ? The Quarterly Journal of Economics, 114(1):263-291, 1999.

T. Hoerger, S. Karon, S. Bernard, K. Tate, R. Lindrooth, T. Waters, and K. Jewell. Evaluation of medicareâs competitive bidding demonstration for dmepos: Final evaluation report. Research Triangle Park NC: RTI International, 2003.

Y. Ji. The impact of competitive bidding in health care: The case of medicare durable medical equipment. 2019.

C. N. Kaufmann, R. Susukida, and C. A. Depp. Sleep apnea, psychopathology, and mental health care. Sleep health, 3(4):244-249, 2017.

W. G. Manning, J. P. Newhouse, N. Duan, E. B. Keeler, and A. Leibowitz. Health insurance and the demand for medical care: evidence from a randomized experiment. The American economic review, pages 251-277, 1987.

J. M. Marin, S. J. Carrizo, E. Vicente, and A. G. Agusti. Long-term cardiovascular outcomes in men with obstructive sleep apnoea-hypopnoea with or without treatment with continuous positive airway pressure: an observational study. The Lancet, 365(9464):1046-1053, 2005. 
W. V. McCall, R. M. Benca, M. E. Rumble, D. Case, P. B. Rosenquist, and A. D. Krystal. Prevalence of obstructive sleep apnea in suicidal patients with major depressive disorder. Journal of psychiatric research, 116:147-150, 2019.

B. Merlob, C. R. Plott, and Y. Zhang. The cms auction: Experimental studies of a median-bid procurement auction with nonbinding bids. The Quarterly Journal of Economics, 127(2):793$827,2012$.

NICE. Continuous positive airway pressure for the treatment of obstructive sleep apnoea/hypopnoea syndrome: Technology appraisal guidance, 2008. https://www .nice.org. uk/guidance/ta139/chapter/4-Evidence-and-interpretation.

K. Ramar, L. C. Dort, S. G. Katz, C. J. Lettieri, C. G. Harrod, S. M. Thomas, and R. D. Chervin. Clinical practice guideline for the treatment of obstructive sleep apnea and snoring with oral appliance therapy: an update for 2015: an american academy of sleep medicine and american academy of dental sleep medicine clinical practice guideline. Journal of clinical sleep medicine, 11(7):773-827, 2015.

C. V. Senaratna, J. L. Perret, C. J. Lodge, A. J. Lowe, B. E. Campbell, M. C. Matheson, G. S. Hamilton, and S. C. Dharmage. Prevalence of obstructive sleep apnea in the general population: a systematic review. Sleep medicine reviews, 34:70-81, 2017.

R. Town and S. Liu. The welfare impact of medicare hmos. RAND Journal of Economics, pages 719-736, 2003. 


\section{Appendix}

Table A1: The Impact of Competitive Bidding on DME Price and Quantity - Lead Items/Categories

\begin{tabular}{lccccc}
\hline \hline & $(1)$ & $(2)$ & $(3)$ & $(4)$ & $(5)$ \\
& Log & Log & Log & Log New & Log \\
& Price & Quantity & Beneficiaries & Beneficiaries & Spending \\
\hline Panel A: Lead Items & & & & & \\
1(Competitive Bidding) & $-0.541^{* * *}$ & $-0.0976^{* * *}$ & $-0.0930^{* * *}$ & $-0.0757 * * *$ & $-0.638^{* * *}$ \\
& $(0.0190)$ & $(0.0199)$ & $(0.0198)$ & $(0.0245)$ & $(0.0158)$ \\
Mean & 113.9 & 52.02 & 18.35 & 3.580 & 6834 \\
$\mathrm{~N}$ & 250,917 & 250,917 & 250,917 & 207,263 & 250,917 \\
\hline Panel B: Category Level & & & & \\
1(Competitive Bidding) & $-0.481^{* * *}$ & $-0.0808^{* * *}$ & $-0.0933 * * *$ & $-0.0858^{* * * *}$ & $-0.562 * * *$ \\
& $(0.0192)$ & $(0.0158)$ & $(0.0140)$ & $(0.0199)$ & $(0.0132)$ \\
Mean & 70.61 & 296.8 & 23.18 & 3.820 & 8788 \\
$\mathrm{~N}$ & 284,080 & 284,080 & 284,080 & 240,038 & 284,080 \\
\hline \hline
\end{tabular}

Notes: This table shows the effect of the CBP on the price and quantity of 12 lead items (Panel A) or product categories (Panel B) in the program. The observation is at product by CBSA by year-quarter level. Treatment indicator $C B P_{p s t}$ is turned on if the item $p$ is included in the CBP in area $s$ during quarter $t$. Since not all products within one category are added into the program in the same time, the treatment variable $C B P_{c s t}$ is not a binary variable, but the percentage of payment for category $c$ in the area $s$ in 2010 that is included in the CBP during quarter $t$. Outcome variables include price, quantity, number of (new) beneficiaries, and total spending, all denominated by one thousand Medicare FFS beneficiaries except price, and all in log terms (the mean of dependant variable shown is in level terms). All regressions include CBSA, product/category, year-quarter fixed effects and their double interactions. All regressions are weighted by the number of claims in each CBSA for each product/category in 2010. Standard errors are clustered at CBSA level. Significance levels: *10\%, **5\%, ***1\%.

Table A2: Robustness Checks - Lead Items

\begin{tabular}{|c|c|c|c|c|c|c|c|c|}
\hline & \multirow{2}{*}{\multicolumn{2}{|c|}{ (1) $1 / 2$ Only }} & \multirow{2}{*}{\multicolumn{2}{|c|}{$\begin{array}{c}(3) \\
\mathrm{R} 1 / 2+\text { Large Non-CBA }\end{array}$}} & (5) & (6) & (7) & (8) \\
\hline & & & & & \multicolumn{2}{|c|}{ State FEs } & \multicolumn{2}{|c|}{ Full Enrollment } \\
\hline & Log Price & Log Quantity & Log Price & Log Quantity & Log Price & Log Quantity & Log Price & Log Quantity \\
\hline 1(Competitive Bidding) & $\begin{array}{l}-0.463 * * * \\
(0.00961)\end{array}$ & $\begin{array}{c}-0.174 * * * \\
(0.0214)\end{array}$ & $\begin{array}{c}-0.492 * * * \\
(0.0140)\end{array}$ & $\begin{array}{c}-0.149 * * * \\
(0.0199)\end{array}$ & $\begin{array}{c}-0.541^{* * * *} \\
(0.0190)\end{array}$ & $\begin{array}{c}-0.0976^{* * * *} \\
(0.0199)\end{array}$ & $\begin{array}{c}-0.539 * * * \\
(0.0192)\end{array}$ & $\begin{array}{c}-0.0869 * * * \\
(0.0247)\end{array}$ \\
\hline Mean & 103.3 & 42.67 & 105.7 & 43.09 & 113.9 & 52.02 & 113 & 41.48 \\
\hline $\mathrm{N}$ & 36,371 & 36,371 & 50,103 & 50,103 & 250,917 & 250,917 & 214,981 & 214,981 \\
\hline Product*YQ FE & Yes & Yes & Yes & Yes & Yes & Yes & Yes & Yes \\
\hline Product*CBSA FE & Yes & Yes & Yes & Yes & Yes & Yes & Yes & Yes \\
\hline CBSA*YQ FE & Yes & Yes & Yes & Yes & Yes & Yes & Yes & Yes \\
\hline State FE & No & No & No & No & Yes & Yes & No & No \\
\hline
\end{tabular}

Notes: This table presents robustness checks for Table A1 Panel A. Basic sample construction and variable definitions are the same. Columns 1-2 further restrict the sample to only round 1 and 2 competitive bidding areas. Columns 3-4 restrict the sample to large non-CBAs (>9000 Medicare FFS population in 2010), round 1 and 2 competitive bidding areas. Columns 5-6 add a state-by-post-CBP indicator which turns on when any place in the state has been included in the CBP to control for state-level policies, including Medicaid. Columns 7-8 restrict attention to Medicare FFS beneficiaries who are enrolled during our entire sample period. All regressions include CBSA, product, year-quarter fixed effects and their double interactions. All regressions are weighted by the number of claims in each CBSA for each product in 2010. Standard errors are clustered at CBSA level. Significance levels: *10\%, **5\%, ***1\%. 


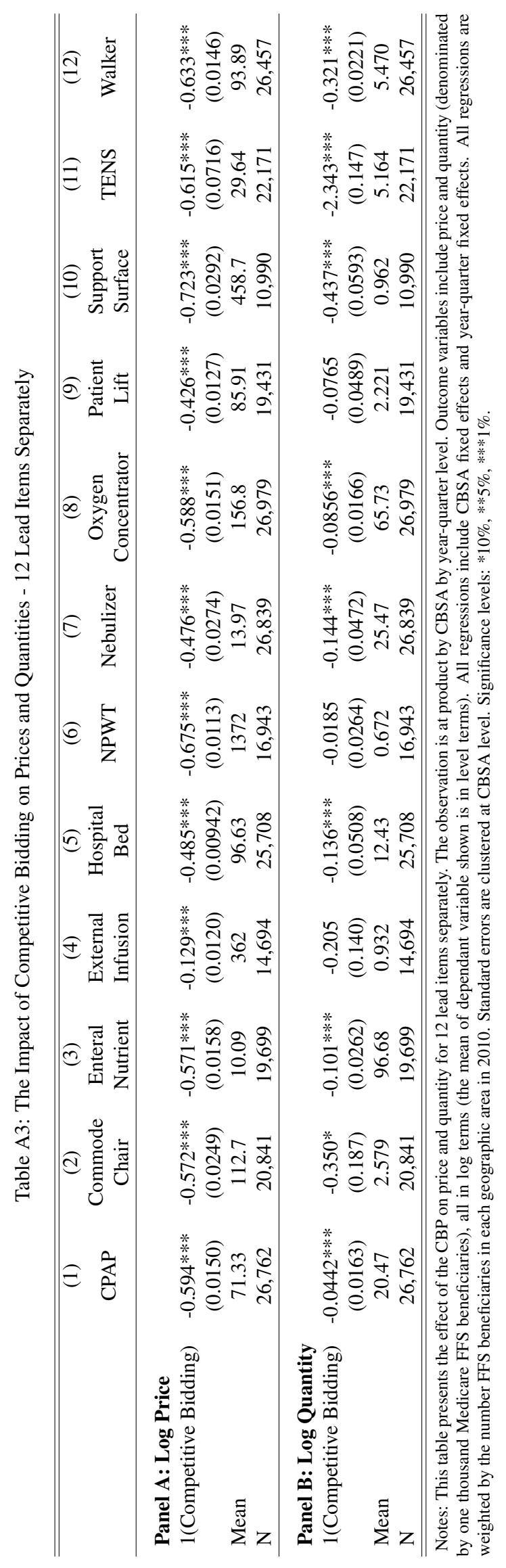


Table A4: Robustness Checks - CPAP

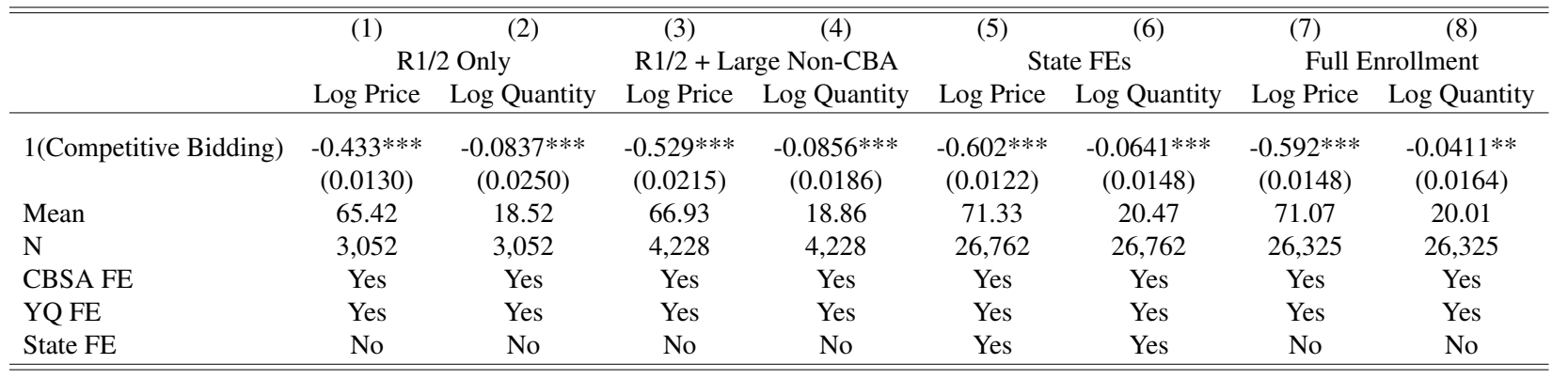

Notes: This table presents robustness checks for Table 4. Basic sample construction and variable definitions are the same. Columns 1-2 further restrict the sample to only round 1 and 2 competitive bidding areas. Columns 3-4 restrict the sample to large non-CBAs ( $>9000$ Medicare FFS population in 2010), round 1 and 2 competitive bidding areas. Columns 5-6 add a state-by-post-CBP indicator which turns on when any place in the state has been included in the CBP to control for state-level policies, including Medicaid. Columns 7-8 restrict attention to Medicare FFS beneficiaries who are enrolled during our entire sample period. All regressions include CBSA fixed effects and year-quarter fixed effects. All regressions are weighted by the number FFS beneficiaries in each geographic area in 2010. Standard errors are clustered at CBSA level. Significance levels: $* 10 \%, * * 5 \%, * * * 1 \%$.

Table A5: The Impact of Competitive Bidding on CPAP Demand - State FEs

\begin{tabular}{lcccc}
\hline \hline & $(1)$ & $(2)$ & $(3)$ & $(4)$ \\
& OOPC & $\begin{array}{c}\text { Log } \\
\text { Quantity }\end{array}$ & $\begin{array}{c}\text { Log } \\
\text { Beneficaries }\end{array}$ & $\begin{array}{c}\text { Log New } \\
\text { Beneficiaries }\end{array}$ \\
\hline Panel A: OLS & & & & \\
1 (Competitive Bidding)*Nondual & $-7.184^{* * *}$ & $0.124^{* * *}$ & $0.114^{* * *}$ & $0.110^{* * *}$ \\
& $(0.174)$ & $(0.0219)$ & $(0.0207)$ & $(0.0229)$ \\
1 (Competitive Bidding) & -0.0337 & $-0.169^{* * *}$ & $-0.157^{* * *}$ & $-0.161^{* * *}$ \\
& $(0.0424)$ & $(0.0246)$ & $(0.0229)$ & $(0.0224)$ \\
\hline Panel B: IV & & & & \\
OOPC & & $-0.0172^{* * *}$ & $-0.0159^{* * *}$ & $-0.0153^{* * *}$ \\
& & $(0.00310)$ & $(0.00292)$ & $(0.00309)$ \\
1 (Competitive Bidding) & & $-0.170^{* * *}$ & $-0.157^{* * *}$ & $-0.161^{* * *}$ \\
& & $(0.0247)$ & $(0.0229)$ & $(0.0224)$ \\
Elasticity & & & & \\
Mean of OOPC (Nondual) & 15.76 & 15.76 & 15.76 & 15.77 \\
$\mathrm{~N}$ & 50,477 & 50,477 & 50,477 & 41,656 \\
State FE & Yes & Yes & Yes & Yes \\
\hline \hline
\end{tabular}

Notes: This table presents robustness checks for Table 7, with state-by-post-CBP fixed effects. The observation is at CBSA by year-quarter by dual/nondual level. Outcome variables include out-of-pocket cost (OOPC, defined as $20 \%$ of price for non-dual and 0 for dual), quantity and number of (new) beneficiaries, all denominated by one thousand Medicare FFS beneficiaries, and all in log terms except OOPC. Panel A shows the OLS result, while Panel B shows the IV result using 1(Competitive Bidding)*Nondual as the instrument for OOPC. All regressions include CBSA fixed effects, year-quarter fixed effects, and their interactions with a dummy variable for dual eligible status. Also included is a state-by-post-CBP indicator which turns on when any place in the state has been included in the CBP to control for state-level policies, including Medicaid. All regressions are weighted by Medicare FFS population in 2010. Standard errors are clustered at CBSA level. Significance levels: *10\%, $* * 5 \%, * * * 1 \%$. 
Table A6: The Impact of Competitive Bidding on CPAP Demand - Full Medicaid Payment

\begin{tabular}{lcccc}
\hline \hline & $(1)$ & $(2)$ & $(3)$ & $(4)$ \\
& OOPC & $\begin{array}{c}\text { Log } \\
\text { Quantity }\end{array}$ & $\begin{array}{c}\text { Log } \\
\text { Beneficiaries }\end{array}$ & $\begin{array}{c}\text { Log New } \\
\text { Beneficiaries }\end{array}$ \\
\hline Panel A: OLS & & & & \\
1 (Competitive Bidding)*Nondual & $-7.815^{* * *}$ & $0.113^{* *}$ & $0.0977^{* *}$ & $0.101^{* *}$ \\
& $(0.220)$ & $(0.0461)$ & $(0.0378)$ & $(0.0391)$ \\
$1($ Competitive Bidding) & -0 & $-0.164 * * *$ & $-0.148^{* * *}$ & $-0.131^{* * *}$ \\
& $(3.87 \mathrm{e}-09)$ & $(0.0521)$ & $(0.0394)$ & $(0.0401)$ \\
\hline Panel B: IV & & & & \\
OOPC & & $-0.0144^{* *}$ & $-0.0125^{* * *}$ & $-0.0129^{* * *}$ \\
& & $(0.00585)$ & $(0.00480)$ & $(0.00487)$ \\
$1($ Competitive Bidding) & & $-0.164 * * *$ & $-0.148^{* * *}$ & $-0.131^{* * *}$ \\
& & $(0.0521)$ & $(0.0394)$ & $(0.0401)$ \\
Elasticity & & & & \\
Mean of OOPC (Nondual) & 16.11 & 16.11 & 16.11 & 16.13 \\
$\mathrm{~N}$ & 20,493 & 20,493 & 20,493 & 16,436 \\
\hline \hline
\end{tabular}

Notes: This table presents robustness checks for Table 7, restricted to states setting the Medicaid rate the same as the Medicare rate or paying dual eligible patients full Medicare OOPC. The observation is at CBSA by yearquarter by dual/nondual level. Outcome variables include out-of-pocket cost (OOPC, defined as $20 \%$ of price for non-dual and 0 for dual), quantity and number of (new) beneficiaries, all denominated by one thousand Medicare FFS beneficiaries, and all in log terms except OOPC. Panel A shows the OLS result, while Panel B shows the IV result using 1(Competitive Bidding)*Nondual as the instrument for OOPC. All regressions include CBSA fixed effects, year-quarter fixed effects, and their interactions with a dummy variable for dual eligible status. All regressions are weighted by Medicare FFS population in 2010. Standard errors are clustered at CBSA level. Significance levels: $* 10 \%, * * 5 \%, * * * 1 \%$. 
Table A7: The Impact of Competitive Bidding on the Demand of 12 Lead Items

\begin{tabular}{|c|c|c|c|c|}
\hline & $\begin{array}{c}(1) \\
\text { OOPC }\end{array}$ & $\begin{array}{c}\text { (2) } \\
\text { Log } \\
\text { Quantity }\end{array}$ & $\begin{array}{c}\text { (3) } \\
\text { Log } \\
\text { Beneficiaries }\end{array}$ & $\begin{array}{c}(4) \\
\text { Log New } \\
\text { Beneficiaries }\end{array}$ \\
\hline \multicolumn{5}{|l|}{ Panel A: OLS } \\
\hline 1(Competitive Bidding)*Nondual & $\begin{array}{c}-10.80 * * * \\
(0.727)\end{array}$ & $\begin{array}{c}0.0328 * * \\
(0.0150)\end{array}$ & $\begin{array}{c}0.02904 * * \\
(0.0132)\end{array}$ & $\begin{array}{c}0.0735 * * * \\
(0.0218)\end{array}$ \\
\hline 1(Competitive Bidding) & 0 & $\begin{array}{c}-0.112 * * * \\
(0.0244)\end{array}$ & $\begin{array}{c}-0.105^{* * * *} \\
(0.0227)\end{array}$ & $\begin{array}{c}-0.114 * * * \\
(0.0226)\end{array}$ \\
\hline \multicolumn{5}{|l|}{ Panel B: IV } \\
\hline OOPC & & $\begin{array}{c}-0.00304 * * \\
(0.00141)\end{array}$ & $\begin{array}{c}-0.00269^{* *} \\
(0.00124)\end{array}$ & $\begin{array}{c}-0.00695 * * * \\
(0.00193)\end{array}$ \\
\hline 1(Competitive Bidding) & & $\begin{array}{c}-0.112 * * * \\
(0.0244)\end{array}$ & $\begin{array}{c}-0.105^{* * *} \\
(0.0227)\end{array}$ & $\begin{array}{c}-0.114 * * * \\
(0.0226)\end{array}$ \\
\hline Elasticity & & -0.0753 & -0.0666 & -0.172 \\
\hline Mean of OOPC (Nondual) & 24.79 & 24.79 & 24.79 & 24.77 \\
\hline $\mathrm{N}$ & 433,409 & 433,409 & 433,409 & 290,542 \\
\hline
\end{tabular}

Notes: This table presents the results of regression analysis for the effect of the CBP on price and quantity of 12 lead items among duals and non-duals. The observation is at product by CBSA by year-quarter by dual/nondual level. Outcome variables include out-of-pocket cost (OOPC, defined as $20 \%$ of price for non-dual and 0 for dual), quantity and number of (new) beneficiaries, all denominated by one thousand Medicare FFS beneficiaries, and all in log terms except OOPC. Panel A shows the OLS result, while Panel B shows the IV result using 1(Competitive Bidding)*Nondual as the instrument for OOPC. All regressions include product by CBSA fixed effects, yearquarter by product fixed effects, CBSA by year-quarter fixed effects, and their interactions with a dummy variable for dual eligible status. All regressions are weighted by the number of claims in each CBSA for each product in 2010. Standard errors are clustered at CBSA level. Significance levels: $* 10 \%, * * 5 \%$, ***1\%. 
Figure A1: The Impact of Competitive Bidding on CPAP Supplier and Market Concentration
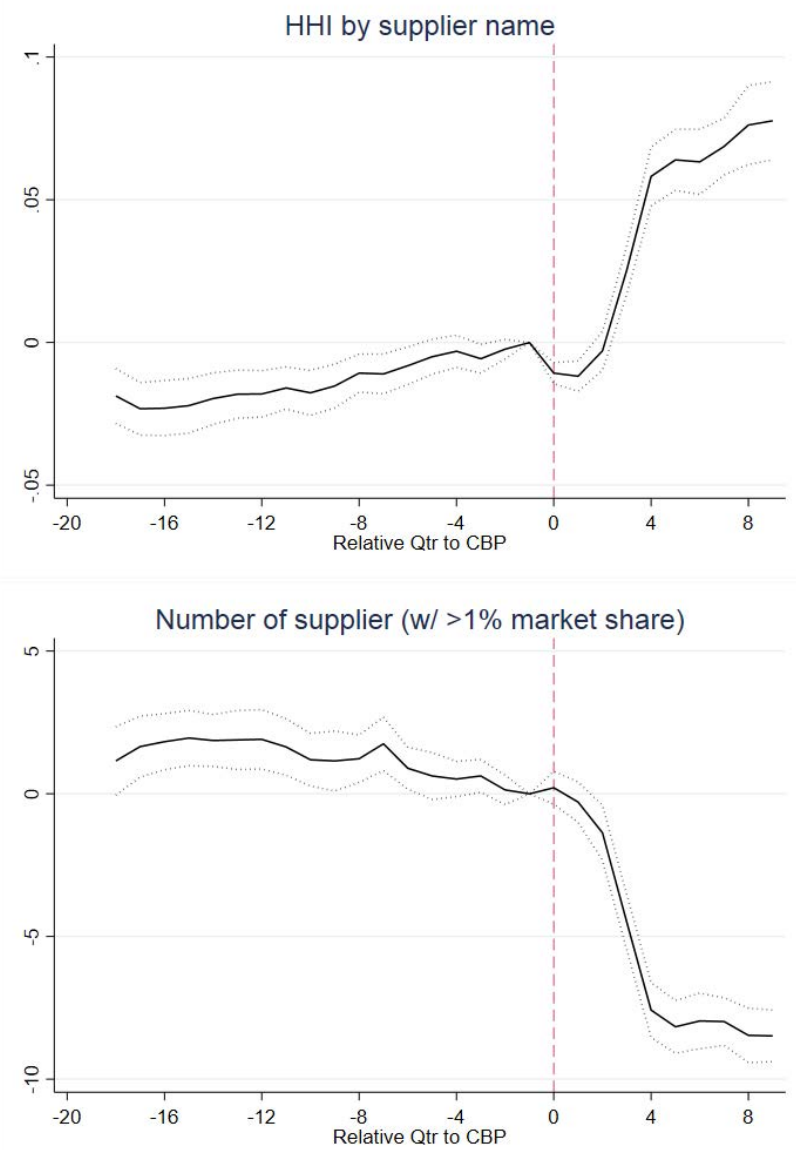

Notes: These figures replicate Figure 2 for CPAP suppliers and market structure. The observation is at CBSA by year-quarter level. Outcome variables include HHI (calculated based on total payments for CPAP), and number of suppliers (with more than $1 \%$ market share based on CPAP payment). All regressions include CBSA fixed effects and year-quarter fixed effects. All regressions are weighted by Medicare FFS population in 2010. The solid line is point estimates for the effect of quarter pre/post-CBP and the dotted lines are the 95 percent confidence interval for those coefficients, based upon standard errors that are clustered at the CBSA level. 
Figure A2: The Impact of Competitive Bidding on Diagnosis
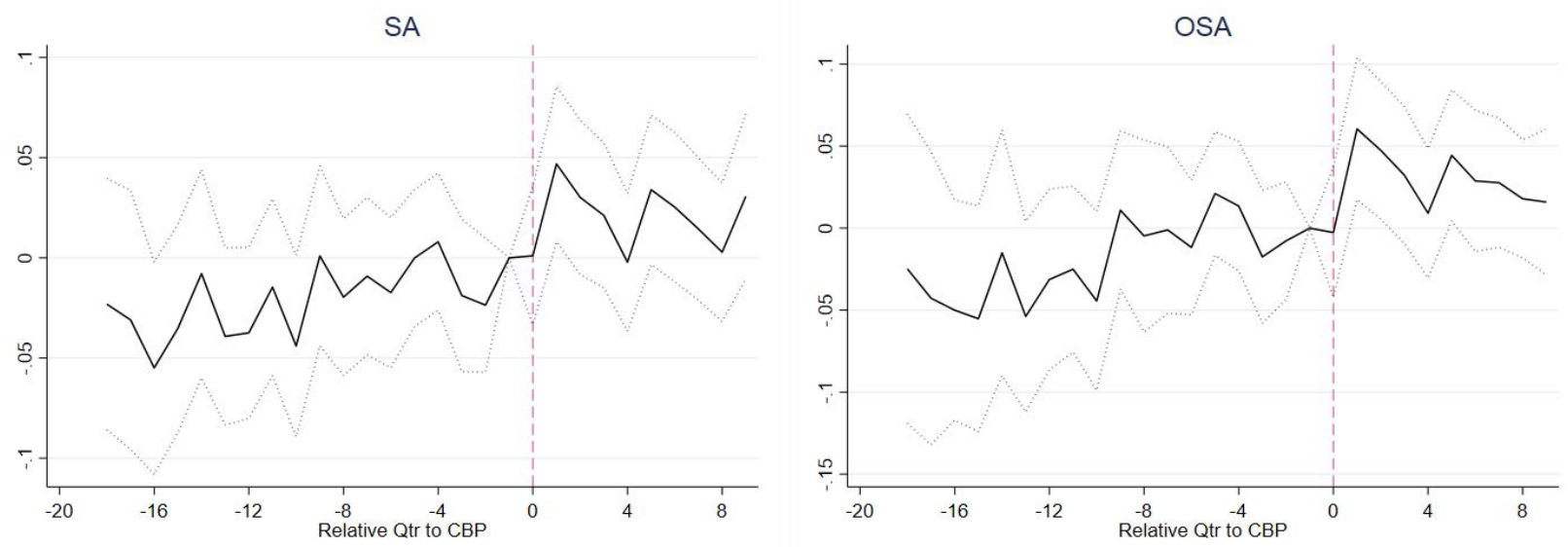

Notes: These figures replicate Figure 2 for the incidence of (obstructive) sleep apnea after the introduction of the CBP. The observation is at CBSA by year-quarter level. Outcome variables are the number of patients newly diagnosed with SA (primary diagnosis recorded as ICD-9 code 327.2 or ICD-10 code G47.3 in inpatient, outpatient or physician carrier table) and OSA (primary diagnosis recorded as ICD-9 code 327.23 or ICD-10 code G47.33) among one thousand Medicare FFS population. The solid line is point estimates for the effect of quarter pre/post-CBP and the dotted lines are the 95 percent confidence interval for those coefficients, based upon standard errors that are clustered by the CBSA level. All regressions include CBSA fixed effects and year-quarter fixed effects. All regressions are weighted by Medicare FFS population in 2010. 


\section{Figure A3: The Impact of Competitive Bidding on Diagnosis}
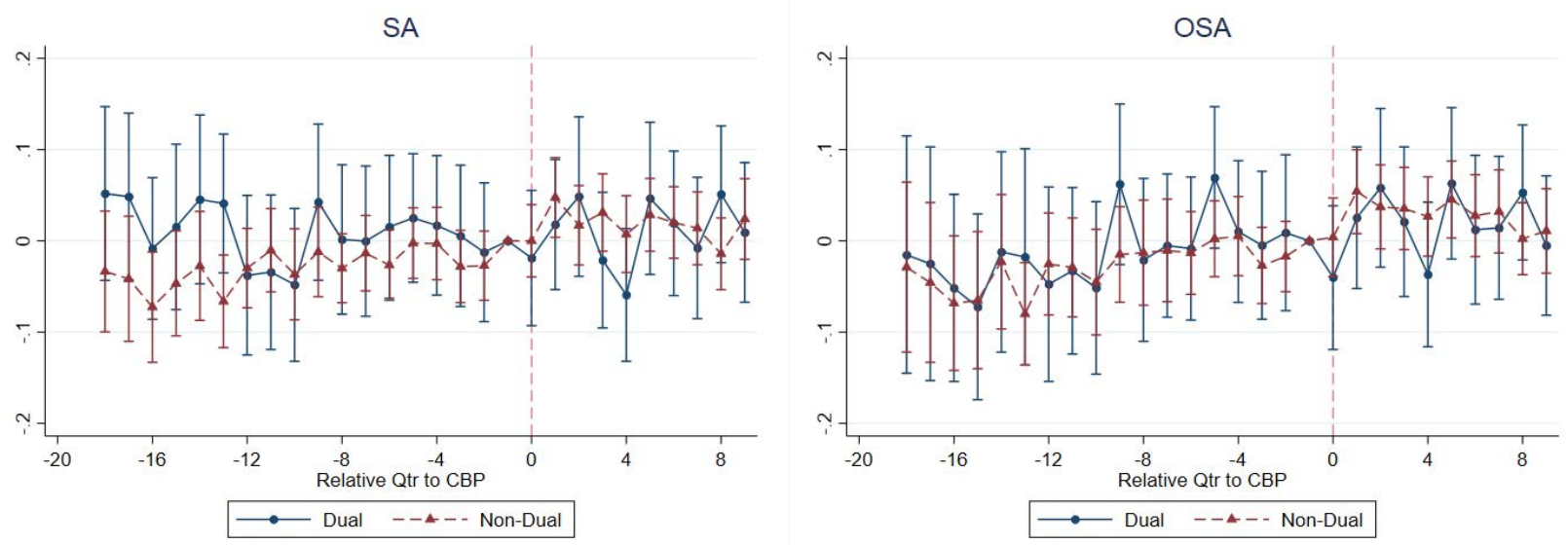

Notes: These figures replicate Figure 3 Panel A for the incidence of (obstructive) sleep apnea after the introduction of the CBP among duals and non-duals separately. The observation is at CBSA by year-quarter by dual/nondual level. Outcome variables are the number of patients newly diagnosed with SA (primary diagnosis recorded as ICD-9 code 327.2 or ICD-10 code G47.3 in an inpatient, outpatient or physician carrier table) and OSA (primary diagnosis recorded as ICD-9 code 327.23 or ICD-10 code G47.33) among one thousand Medicare FFS population. Coefficients of relative years interacting with dual indicator are plotted. The blue solid lines show point estimates for the effect of the CBP for duals and the red dashed lines show point estimates for non-duals. Vertical lines show the 95 percent confidence interval for those coefficients, based upon standard errors that are clustered at the CBSA level. All regressions include CBSA fixed effects, year-quarter fixed effects, and their interactions with dummy variable for each group. All regressions are weighted by Medicare FFS population in 2010. 